NBER WORKING PAPER SERIES

\title{
CENTRAL BANK POLICY AND THE CONCENTRATION OF RISK: EMPIRICAL ESTIMATES
}

\author{
Nuno Coimbra \\ Daisoon Kim \\ Hélène Rey \\ Working Paper 28907 \\ http://www.nber.org/papers/w28907 \\ NATIONAL BUREAU OF ECONOMIC RESEARCH \\ 1050 Massachusetts Avenue \\ Cambridge, MA 02138 \\ June 2021, Revised September 2021
}

We are very grateful for the comments of the Editor, an anonymous referee, our discussant Nina Boyarchenko and of the participants in the 2021 Carnegie-Rochester-NYU Public Policy Conference. Rey thanks the ERC for financial support (ERC Advanced Grant 695722). The views expressed in this paper are those of the authors and do not necessarily represent those of the Banque de France, the ESCB, or the French Macroprudential Authority. The views expressed herein are those of the authors and do not necessarily reflect the views of the National Bureau of Economic Research.

NBER working papers are circulated for discussion and comment purposes. They have not been peer-reviewed or been subject to the review by the NBER Board of Directors that accompanies official NBER publications.

(C) 2021 by Nuno Coimbra, Daisoon Kim, and Hélène Rey. All rights reserved. Short sections of text, not to exceed two paragraphs, may be quoted without explicit permission provided that full credit, including $\odot$ notice, is given to the source. 
Central Bank Policy and the Concentration of Risk: Empirical Estimates

Nuno Coimbra, Daisoon Kim, and Hélène Rey

NBER Working Paper No. 28907

June 2021, Revised September 2021

JEL No. E0,E5,F3,G01

\begin{abstract} stability.

Nuno Coimbra

Banque de France

39, Rue Croix des Petits Champs 75001 Paris

France

nuno.coimbra@banque-france.fr

Daisoon Kim

Nelson Hall 4114, Box 8110

Poole College of Management

North Carolina State University

Raleigh, NC 27695

dkim29@ncsu.edu

Hélène Rey

London Business School

Regents Park

London NW1 4SA

United Kingdom

and CEPR

and also NBER

hrey@london.edu
\end{abstract}

Before the 2008 crisis, the cross-sectional skewness of banks' leverage went up and macro risk concentrated in the balance sheets of large banks. Using a model of profit-maximizing banks with heterogeneous Value-at-Risk constraints, we extract the distribution of banks' risk-taking parameters from balance sheet data. The time series of these estimates allow us to understand systemic risk and its concentration in the banking sector over time. Counterfactual exercises show that (1) monetary policymakers confront the trade-off between stimulating the economy and financial stability, and (2) macroprudential policies can be effective tools to increase financial 


\section{Introduction}

Financial crises are a recurring phenomenon in economic history. Their consequences on growth and investment can be severe and protracted, as the Great Financial Crisis of 2008 so clearly illustrated. Eichengreen and Portes (1987) write that "much as the study of disease is one of the most effective ways to learn about human biology, the study of financial crises provides one of the most revealing perspectives on the functioning of monetary economies." There is now substantial evidence showing that credit expansions can end in crashes materializing in banking crises and recessions, (e.g., Borio and Lowe, 2002; Mian and Sufi, 2009; Schularick and Taylor, 2012; Fouliard, Howell and Rey, 2020). However, the mechanism and characteristics of credit expansions as well as their root causes remain largely elusive. Making progress on those fronts is key for policymakers in charge of macroprudential policies.

This paper starts with three important facts. First, there is substantial heterogeneity in risk-taking across financial intermediaries, particularly during credit booms, and some large actors are particularly reckless. Leverage increases on average in the financial system during booms, but some banks gain market share rapidly. Wilmarth (2014) for the US before 2008, Englund (2016) for Sweden before 1992, Santos (2017) and Hellwig (2018) for Spain and Germany respectively before 2008 all show in their case studies on crises that a subset of large actors took excessive amounts of macro risk before the crash. For example, Deutsche Bank leveraged up to quadruple the size of its balance sheet from about $€ 0.5$ trillion in early 1990s to about $€ 2$ trillion in 2008 as a return of equity (RoE) of $25 \%$ was regularly targeted by the bank CEO. Second, as explained in Adrian and Shin (2010); Adrian and Boyarchenko (2012); Stulz (2016), banks and other financial institutions make extensive use of value-at-risk (VaR) measures to manage their risk. Firms estimate the probability of making losses that could put them in financial distress or default. A certain amount of losses that is exceeded with a probability $p$ over one month gives the VaR over one month at the probability level $p$. 
The use of VaR is ubiquitous in the financial sector. Third, there is great variation across financial intermediaries regarding how $\mathrm{VaR}$ is calculated and how internal risk models of banks are evaluated. A prima facie example of that variation is the exercise performed by the Basel Committee on Banking Supervision, who undertook a review of the consistency of risk weights used by a sample of banks (Basel Committee on Banking Supervision, 2013). Those risk weights, for a given portfolio, depend on the internal risk models of the different institutions. When given a diversified test portfolio, the surveyed banks, who knew they were answering their regulators, produced a wide range of results in terms of modeled VaR and gave answers ranging from 13 million to 33 million euros in terms of capital requirement with a median of about 18 million. These differences in VaR modeling may be reflecting corporate culture (risk appetite of the boards as discussed by Stulz, 2016) or different interactions between banks and their national supervisors, some being much more prescriptive than others. The tightness of VaR constraints varies substantially across institutions.

In this paper, we zoom on this heterogeneity in risk-taking by analyzing the evolution of the cross-sectional composition of the balance sheets of financial intermediaries. We estimate the distribution of their VaR constraint parameters and show how they change over time as macroeconomic conditions and regulations fluctuate. We show that the time variation and the shape of the estimated distributions of the VaR parameters are excellent predictors of bank performance and carry important information on systemic risk. Importantly, it is crucial to consider the heterogeneity across different financial intermediaries as the larger share of time variation in our measure comes from the cross-section. Simply looking at changes in aggregate leverage in the system would therefore miss an essential part of the story. As an aside, our measure outperforms those based on asset prices when predicting aggregate risk. In line with this, our systemic risk indicator is related to Baron and Xiong (2017) who link bank credit expansion to negative predicted excess returns of the bank equity index in the next three years, but we estimate structural parameters at the bank level rather than outcome variables at the country level. 


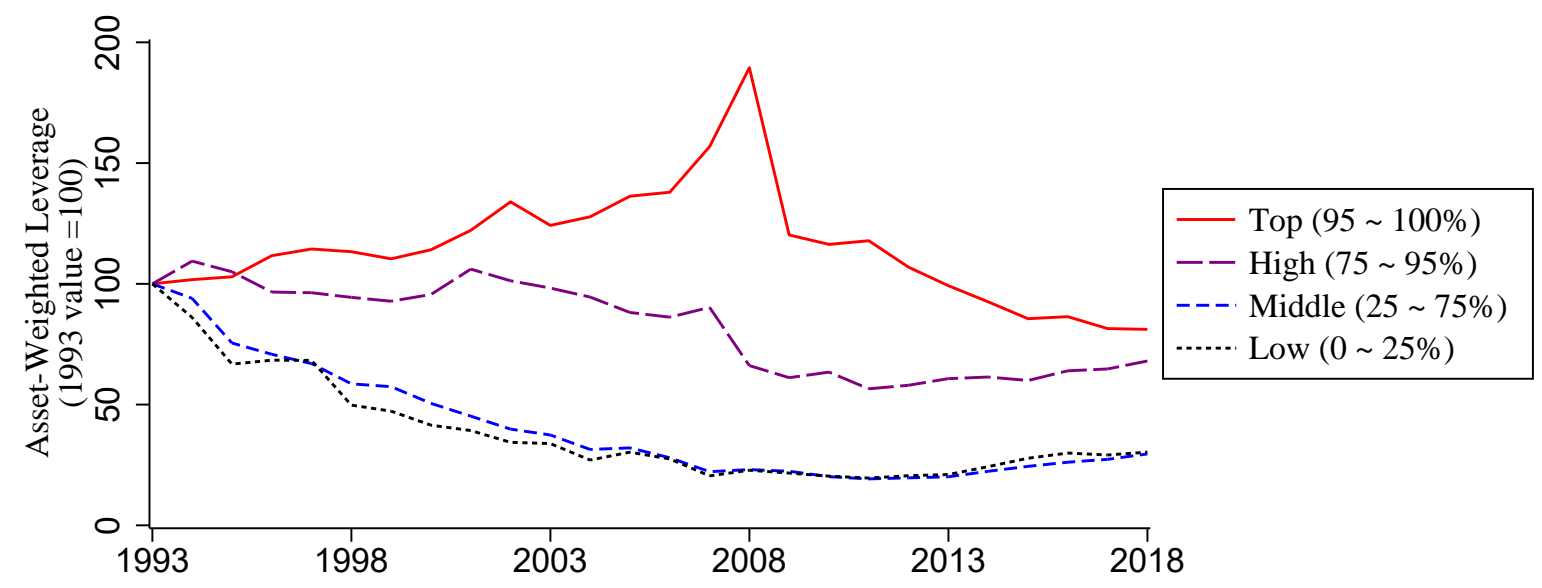

Figure 1: Evolution of leverage by quantiles: The figure plots the average of the asset weighted leverage by quantiles. Values were rebased to 100 for the starting year 1993, to highlight the stark difference in dynamics. See Figure A1 for unweighted leverage by quantiles.

Figure 1 presents the time series of asset-weighted leverage for quantiles of a broad cross-section of financial intermediaries worldwide. There is clearly substantial heterogeneity in the cross-sectional dynamics of asset-weighted leverage. In the build-up to the 2008 crisis, the intermediaries that were already the most leveraged were the ones that increased asset-weighted leverage the most, while the middle and lower quantiles tended to decrease their asset-weighted leverage during this period. This indicates that the rise in asset-weighted leverage pre-crisis was driven primarily by large, highly levered intermediaries and not by small ones with little macroeconomic importance.

Simply looking at changes in leverage to assess systemic risk could however be misleading as the implications for financial stability can be very different depending on the main driver behind such changes. In the words of Gorton and Ordoñez (2019), there are good booms and bad booms. For example, if changes in growth and investment opportunities are driving leverage, that might have very different implications from a case where leverage is being driven by a rise in the supply of credit by intermediaries due to low cost of funds or a rise in risk appetite. By using a structural model, we can make progress on those issues. Coimbra and Rey (2020) develop a full general equilibrium model of good booms and bad booms and 
of the risk-taking channel of monetary policy.

Our empirical strategy relies on two assumptions: i) leveraged financial intermediaries maximize profits under their specific VaR constraints, and ii) the VaR parameters follow a time-varying Beta distribution. We use a maximum likelihood approach applied to Compustat Fundamentals Annual data from 1993 to 2018 to estimate the distribution of VaR parameters from leverage data. The estimated risk-taking behavior closely relates to observed intermediaries' distress and to both market and book returns, providing external validity to our estimates.

We then use the results to understand how changes in the distribution of risk-taking affect financial instability. Aggregate systemic risk - the probability of a systemic crisis occurring - can be measured by the asset-weighted mean of VaR parameters. An individual intermediary's contribution to our systemic risk measure is then a combination of its size and balance sheet risk. Our measure indicates that systemic risk is very concentrated, with the top $5 \%$ intermediaries contributing to about $71 \%$ of the total value on average and also driving most of the variation over time. Also, we find strong evidence that it is crucial to account for heterogeneity in macro-finance research. A measure consisting of a representative intermediary with average leverage would only explain around $28 \%$ of the systemic risk measure.

Our measure complements previous empirical studies on systemic risk. Closest to our approach is Duarte and Eisenbach (2021) who, like us, emphasize the importance of heterogeneity in intermediation and use cross-sectional information from banks' balance sheets to construct measures of systemic risk. Both our papers also underline the importance of leverage to capture financial vulnerability. Duarte and Eisenbach (2021) perform a rich analysis using disaggregated data at the asset class level for US banks. They decompose aggregate vulnerability into fire-sale-specific factors (including deleveraging speed) by exploiting not only the cross-section but also the information contained in the time series of their US bank panel. In contrast, our empirical approach is structural and is underpinned by a VaR 
framework. Thus, we can recover the key behavior/characteristic of financial intermediaries (degree of risk-taking) estimated year by year. This allows us to deal with breaks in the time series, and importantly to analyze the effect of policy changes and run counterfactual experiments.

We find that systemic risk increased between 2000 and 2008 as liquidity was abundant in the global economy and regulatory policies were loose. It decreased after the financial crisis when banking regulations were gradually tightened. According to our structural interpretation, changes in the distribution of risk-taking pre-crisis were driven by a fall in the cost of funds (due in part to the abundance of world savings and loose monetary policy) and weak bank and financial markets regulation. We perform two counterfactual exercises, one where we consider what would have happened with higher costs of funds; and another one without changes in the regulatory environment post-crisis. The recent decline of systemic risk measures stems from changes in the post-global financial crisis's regulatory environment. Monetary policy faces a trade-off between stimulating the economy (low interest rate, low cost of funds) and financial stability. Low interest rates generate incentives for intermediaries to borrow, which increases systemic risk, but also may be necessary from the point of view of economic activity. These results suggest that macroprudential policy can serve as a useful complement to monetary policy. ${ }^{1}$

The paper is organized as follows: Section 2 presents a framework and estimation strategy for investigating heterogeneity in risk-taking behavior. Section 3 documents the estimation results and validation of our framework. Section 4 provides evidence on systematic relationships among risk-taking behavior, bank performance, and financial crisis. Section 5 analyzes systemic risk. In Section 6, we explore different counterfactuals in order to better understand the role of monetary policy and regulatory policy changes. Section 7 concludes.

\footnotetext{
${ }^{1}$ See Coimbra and Rey (2020); Caballero and Simsek (2020) for theoretical discussions about these issues.
} 


\section{A Framework with Heterogeneity in Risk-Taking}

\section{1. $\quad$ Model}

This section presents our empirical framework to analyze the heterogeneous risk-taking behavior of financial intermediaries. Consider a financial sector composed of a continuum of financial intermediaries in a competitive environment. An intermediary $i$ is a risk-neutral agent that maximizes its profit subject to a Value-at-Risk (VaR) constraint. This constraint imposes that intermediary $i$ chooses an investment strategy such that the probability its return on equity is negative is smaller than an intermediary-specific parameter $\alpha_{i, t}$. A large $\alpha_{i, t}$ will therefore denote a high risk tolerance while a low $\alpha_{i, t}$ will characterize a more conservative bank. Specifically, the VaR constraint can be written as:

$$
\operatorname{Pr}\left(\pi_{i, t+1}<\omega_{i, t}\right) \leq \alpha_{i, t} .
$$

This condition imposes that intermediary $i$ invests in such a way that the probability of distress - negative returns on equity - must be no greater than an intermediary-specific threshold parameter $\alpha_{i, t}$. Negative returns on equity occur when its cash flow $\pi_{i, t+1}$ is smaller than starting equity $\omega_{i, t}$. We assume that the idiosyncratic return of assets $r_{i, t+1}^{a}$ is an independent and identically distributed random variable $Z_{t+1}$. The conditional mean and variance of $\ln Z_{t+1}$ are $\mu_{Z, t}$ and $\sigma_{Z, t}^{2}$, respectively. The deposit (debt) $d_{i, t}$ is contracted at the costs of funds (interest rate) $r_{t}^{d}$. The cash flow, thus, is $\pi_{i, t+1}=\omega_{i, t}+r_{i, t+1}^{a} a_{i, t}-r_{t}^{d} d_{i, t}$ where $a_{i, t}$ are total assets. For a participating intermediary $i$, the VaR constraint binds because of risk neutrality ${ }^{2}$. For convenience, introduce $Z_{t+1}^{e}=\exp \left(\mu_{Z, t}\right)$. After some straightforward algebra, we obtain the following equation that links the leverage $\lambda_{i, t}$, defined as assets divided

\footnotetext{
${ }^{2}$ In Coimbra and Rey (2020), intermediaries endogenously choose whether to participate or not in the market for risky projects. They also choose how much to leverage based on macroeconomic conditions and their characteristics. Non participating intermediaries invest in a safe storage technology.
} 
by equity, to the threshold $\alpha_{i, t}$

$$
\lambda_{i, t} \equiv \frac{a_{i, t}}{\omega_{i, t}}=\frac{r_{t}^{d}}{r_{t}^{d}-Z_{t+1}^{e} Q_{t}\left(\alpha_{i, t}\right)}
$$

where we define $Q_{t}(\cdot)$ by the quantile function (inverse cumulative distribution function) of $Z_{t+1} / Z_{t+1}^{e}$. The mapping between leverage and the parameter $\alpha_{i, t}$ varies systemically with macroeconomic fundamentals: expected asset returns, interest rate, and uncertainty.

Equation (2) allows us to use the leverage of financial intermediaries observed in the data and the VaR constraint to infer risk-taking and fundamental macroeconomic parameters. The equation can be rewritten in terms of the debt-to-asset ratio $\psi_{i, t}$ which can be conveniently expressed as follows. ${ }^{3}$

$$
\psi_{i, t} \equiv 1-\frac{1}{\lambda_{i, t}}=\zeta_{t} Q_{t}\left(\alpha_{i, t}\right)
$$

where $\zeta_{t}=Z_{t+1}^{e} / r_{t}^{d}$ is the ratio of the expected returns of assets to the cost of funds. $\zeta_{t}$ and $Q_{t}(\cdot)$ embeds some macroeconomic variables such as the expected volatility of returns. $Q_{t}(\cdot)$ falls ceteris paribus when volatility rises so that a bank needs to decrease leverage if it wants to keep constant its level of risk-taking. Coimbra and Rey (2020) show that VaR constraints get looser when the cost of funds is low and volatility is low (low $\sigma_{Z, t}^{2}$ ), and that such conditions enable the more risk-tolerant intermediaries to leverage up massively. When interest rates are low or when the volatility of returns is low, the probability of distress is lower, ceteris paribus. In that region, increases in leverage translate into small increases in the probability of distress, which implies that intermediaries can increase leverage by sizable amounts until they hit the VaR constraint. Similarly, for looser VaR constraints, leverage can be increased a lot before the constraint is hit. Thus, the most risk-taking intermediaries' leverage will respond more to changes in the cost of funds. This heterogeneity of leverage to

\footnotetext{
${ }^{3}$ Since the debt-to-asset ratio is bounded between 0 and 1 , its moments always exist. However, leverage can be theoretically infinite. Its upper tail is fat, thus some moments do not exist.
} 
changes in the cost of funds means a more skewed cross-sectional distribution of leverage as interest rates fall. This generates a composition effect, where the proportion of assets being held by the more risk-taking intermediary rises. Since the intensive margin effect is more significant with low interest, it follows that this composition effect is particularly strong at low interest rates.

\subsection{Estimation Strategy}

To make use of the structure of our model, we make two parametric assumptions, which are very general. We first assume that $\ln Z_{t+1}$ follows a logistic distribution with parameters $\left(\mu_{Z, t}, \sigma_{Z, t}^{*}\right)$. Its mean and standard deviation are thus $\mu_{Z, t}$ and $\sigma_{Z, t}=\pi \sigma_{Z, t}^{*} / \sqrt{3}$, respectively. $Z_{t+1} / Z_{t+1}^{e}$ therefore follows the log-logistic distribution with parameters $\left(0, \sigma_{Z, t}^{*}\right)$, and the quantile function $Q_{t}$ is given by $Q_{t}(p)=[p /(1-p)]^{\sigma_{Z, t}^{*}}$. Second, we assume that the crosssectional distribution of risk-taking ability (VaR threshold) follows a Beta distribution: $\alpha_{i, t} / \alpha_{t}^{\mathrm{ub}} \sim \operatorname{Beta}\left(\phi_{L, t}, \phi_{R, t}\right)$ on $(0,1)$ where $\alpha_{t}^{\mathrm{ub}} \leq 1$ is the upper bound of $\alpha_{i, t}$ for period $t$. Beta distributions are widely used in statistical models of bounded random variables due to their flexibility. Note that $\alpha_{t}^{u b}$ is the upper bound of the support of $\alpha_{i, t}$ at $t$ so will in general be larger than the (finite) sample maximum. $\phi_{L, t}$ and $\phi_{R, t}$ are shape parameters for the left and right tails, respectively. ${ }^{4}$ The shape of the right tail parameterizes the concentration of risk on the balance sheet of the most risk-taking intermediaries. This is a particularly important parameter as the larger the mass of high risk intermediaries, the less financially stable the economy.

Given our parametric assumptions, the debt-to-asset ratio follows the McDonald and $\mathrm{Xu}$ (1995)'s five parameters generalized beta distribution with $\boldsymbol{\Phi}_{t}=\left\{\phi_{p, t}, \phi_{s, t}, \phi_{c, t}, \phi_{L, t}, \phi_{R, t}\right\}$, where $\left\{\phi_{p, t}, \phi_{s, t}, \phi_{c, t}, \phi_{L, t}, \phi_{R, t}\right\}=\left\{1 / \sigma_{Z, t}^{*}, \zeta_{t}\left(\alpha_{t}^{\mathrm{ub}}\right)^{\sigma_{Z, t}^{*}}, \alpha_{t}^{\mathrm{ub}}, \phi_{L, t}, \phi_{R, t}\right\} .{ }^{5}$ The generalized beta

\footnotetext{
${ }^{4}$ The probability density function $(\mathrm{PDF})$ is $x^{\phi_{L, t}-1}(1-x)^{\phi_{R, t}-1} / \mathrm{B}\left(\phi_{L, t}, \phi_{R, t}\right)$ on $(0,1)$, where $\mathrm{B}(y, z)=$ $\int_{0}^{1} w^{y-1}(1-w)^{z-1} d w$ is the (complete) beta function.

${ }^{5} \mathrm{We}$ are interested in a random variable on a non-negative support. Thus, we assume that $\phi_{p, t}$ and $\phi_{s, t}$ are positive. However, the original five parameter generalized beta distribution does not restrict $\phi_{p, t}$ and $\phi_{s, t}$, and it can have a negative support. See McDonald and Xu (1995) for details of the five parameter generalized beta distribution. Also, see McDonald (1984); Cummins et al. (1990); McDonald and Xu (1995);
} 
distribution nests many distributions used in economics and finance, for example, the Burr, gamma, beta, log normal, Weibull, log-logistic, Pareto, uniform, and exponential distributions. Therefore, despite our parametric assumptions, the shape of the distribution of $\alpha_{i, t}$ is relatively unrestricted and is mostly determined by the underlying data itself. The probability density function (pdf) is

$$
\operatorname{pdf}_{\psi}\left(x \mid \boldsymbol{\Phi}_{t}\right)=\frac{\phi_{p, t} x^{\phi_{p, t} \phi_{L, t}-1}\left[1-\left(1-\phi_{c, t}\right)\left(x / \phi_{s, t}\right)^{\phi_{p, t}}\right]^{\phi_{R, t}-1}}{\left(\phi_{s, t}\right)^{\phi_{p, t} \phi_{L, t}} \mathrm{~B}\left(\phi_{L, t}, \phi_{R, t}\right)\left[1+\phi_{c, t}\left(x / \phi_{s, t}\right)^{\phi_{p, t}}\right]^{\phi_{L, t}+\phi_{R, t}}}
$$

on $\left(0, \phi_{s, t} /\left(1-\phi_{c, t}\right)^{1 / \phi_{p, t}}\right)$. From our structural model, it follows that the power $\phi_{p, t}$ and scale parameters $\phi_{s, t}$ are positive and we include that restriction in the estimation. The parameter $\phi_{c, t}$ determines the class of distribution: values $\phi_{c, t} \rightarrow 0$ and $\phi_{c, t} \rightarrow 1$ imply beta distributions of the first and second kind, respectively. $\phi_{L, t}$ and $\phi_{R, t}$ are the left and right tail shape parameters, respectively. The tails of the risk-taking distribution determine the tails of the debt-to-asset ratio distribution. This property allows us to recover the risk-taking distribution $\left(\alpha_{i, t}\right)$ by parametric estimations from the observed debt-to-asset ratios $\left(\psi_{i, t}\right)$.

Rather than assuming a particular time series-structure for the parameters, we estimate $\boldsymbol{\Phi}_{t}$ each year using a weighted maximum likelihood (ML) method:

$$
\begin{aligned}
& \hat{\boldsymbol{\Phi}}_{t}=\arg \max _{\mathbf{\Phi}_{t}} \sum_{i} w_{i, t} \times \ln \operatorname{pdf}_{\psi}\left(\psi_{i, t} \mid \boldsymbol{\Phi}_{t}\right) \quad \text { on } \quad\left(0, \psi_{t}^{\mathrm{ub}}\right) \\
& \quad \text { subject to } \phi_{p, t}, \phi_{s, t}, \phi_{L, t}, \phi_{R, t}>0, \phi_{s, t}<2, \phi_{c, t}=1-\left(\phi_{s, t} / \psi_{t}^{\mathrm{ub}}\right)^{\phi_{p, t}}, \text { and } \psi_{t}^{\mathrm{ub}}=1 .
\end{aligned}
$$

The log-likelihood function is weighted by log size (measured by assets) so that we take into account that larger intermediaries are economically more important than smaller ones. ${ }^{6}$

We restrict the parameter space so that the distribution is defined only when $\phi_{L, t}, \phi_{R, t}$, and $\phi_{s, t}$ are positive as in standard generalized Beta distributions. Since $\alpha_{t}^{\mathrm{ub}}$ should be less

Parker (1999); Cowell and Flachaire (2015); Kakamu and Nishino (2019); Higbee and McDonald (2021) for applications of the generalized beta distribution.

${ }^{6}$ We also performed an unweighted estimation. All the main results are robust. 
than one, we obtain $\phi_{s, t}<\zeta_{t}$, where $\zeta_{t}$ defined in equation (3) is the spread, i.e., the ratio of expected returns on assets over the cost of funds. Thus, setting the upper bound on $\zeta_{t}$ to two (which implies $\phi_{s, t}<2$, is equivalent to setting an upper bound on the margin of above one hundred percentage points, which is again quite unrestrictive. The restriction on $\phi_{c, t}$ derives from the support of distribution: $\psi_{t}^{\mathrm{ub}}=\phi_{s, t} /\left(1-\phi_{c, t}\right)^{1 / \phi_{p, t}}$. We fix the upper bound of the debt-to-asset ratio at one because the maximum debt-to-asset ratio we observe during any year is almost one.

Before applying the ML procedure to the balance sheet data, we drop intermediaries with leverage in the bottom ten percent of our sample over the whole period ${ }^{7}$. Our specification relies on the model-derived binding VaR constraint faced by endogenously-levered financial intermediaries in the previous section. However, some intermediaries' VaR constraints might not be binding: in the structural model of Coimbra and Rey (2020) there is a cutoff value of the VaR threshold, below which an intermediary $j$ will choose not to leverage up to its constraint. $^{8}$ For those intermediaries, the VaR constraint does not bind, and our empirical strategy is not suitable for the estimation. We, therefore, drop the low leverage (debt-toasset ratio) intermediaries in the estimation stage. However, after the ML estimation, the construction of our systemic risk measure and counterfactual analysis use the entire sample.

\section{Heterogeneous Intermediaries and Their Distribution}

This section applies the ML procedure to the balance sheet data of financial intermediaries. Compustat Fundamentals Annual data from 1993 to 2018 yields a yearly sample with 484 observations on average and with observation counts ranging from 448 to $521 .{ }^{9}$ We also impose certain filtering criteria such as, for example, excluding observations with negative

\footnotetext{
${ }^{7}$ We also performed robustness checks with the bottom 5 percent

${ }^{8}$ The cutoff systemically varies with economic conditions. Thus we drop the bottom five or ten percent of our whole period sample, not each year.

${ }^{9}$ We report summary statistics in Figures A2 - A4. Table A1's Panel A also provides information on the identity, leverage and balance sheet size of the 20 largest intermediaries in 2008 and their respective values for 2006 and 2010.
} 

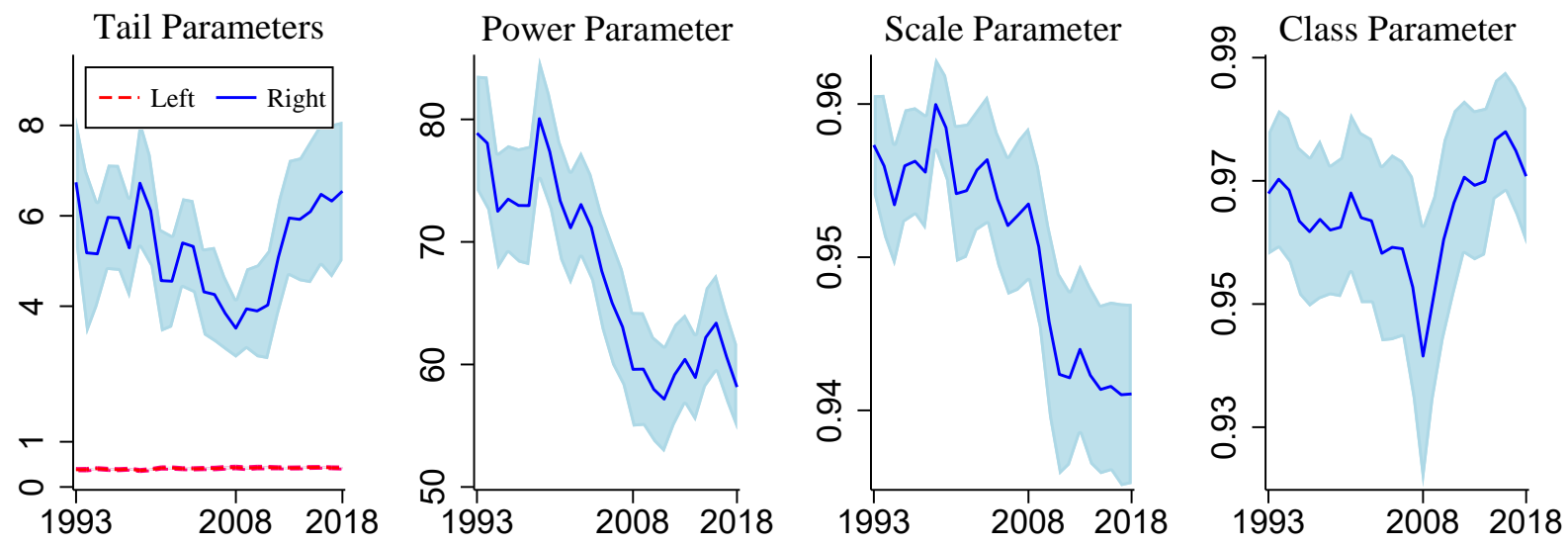

Figure 2: Estimated Parameters: The figure plots the MLE results of the distribution of the debt-to-asset ratio $\psi_{i, t}$. In all figures, the shades are $95 \%$ intervals with robust standard errors. In the first figure, the blue solid and red dashed lines report estimates of the right- and left-tail parameters. The second figure reports the estimated power parameter. The third and fourth figures report the estimated scale and class parameters.

equity or negative assets. Appendix A provides more details on the sample used.

Figure 2 describes estimates of the generalized beta distribution and their variation over time. ${ }^{10}$ There is important time variation in the right tail parameter, as well as in the power and scale parameters. We discuss their economic implications below. In Appendix B, Figure A5 shows our estimated distribution of debt-to-asset ratios for each year. Overall the fit seems quite good, which shows the benefit of using a highly flexible and general class of distributions for our estimation.

Once we have estimated the distribution parameters, we can use observed leverage to recover the implied risk-taking of each intermediary $i$ using equation (2):

$$
\hat{\alpha}_{i, t}=\alpha\left(\lambda_{i, t} \mid \hat{\Phi}_{t}\right)=\frac{\hat{\phi}_{c, t}\left(1-1 / \lambda_{i, t}\right)^{\hat{\phi}_{p, t}}}{\left(\hat{\phi}_{s, t}\right)^{\hat{\phi}_{p, t}}+\hat{\phi}_{c t}\left(1-1 / \lambda_{i, t}\right)^{\hat{\phi}_{p, t}}},
$$

where the function $\alpha\left(\lambda_{i, t} \mid \hat{\Phi}_{t}\right)$ is independent of the left and right tail parameters $\hat{\phi}_{L, t}$ and $\hat{\phi}_{R, t}$, respectively. Conditional on the estimated parameters in equation (5), concentration in

\footnotetext{
${ }^{10}$ See Table A2 in Appendix B for some summary statistics of the estimates.
} 


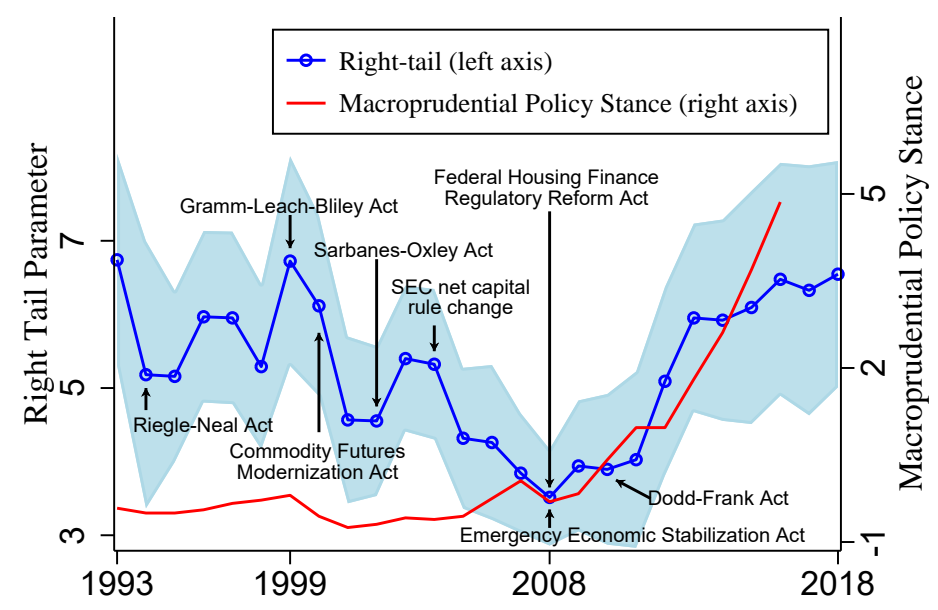

Figure 3: Right-tail Parameter, Macroprudential Policy Stance, and Changes in Banking Regulation: The figure plots estimated $\phi_{R, t}$ from the estimation results (blue line with circles) with $95 \%$ intervals (light blue shades), the average macroprudential policy stance of advanced countries (red line) measured by Forbes (2021). We also indicates major changes in US banking regulation.

risk-taking emerges from the concentration in leverage. Of course, all parameter estimates are dependent on the entire sample distribution for each year.

In Figure 2, we observe that $\phi_{L, t}$ is smaller than one, while $\phi_{R, t}$ is greater than one for all periods. These results imply that the density of $\alpha_{i, t}$ is strictly decreasing, as Figure 4 shows. We find that the risk-taking of financial intermediaries is right (i.e., positively) skewed. Dynamically, the left tail parameter is quite stable over time, while there is significant variation in the right tail. Before the financial crisis, the right tail parameter decreased, implying a thicker right tail in the risk-taking distribution. A low right tail parameter implies more intermediaries taking high risks. ${ }^{11}$ As we can infer from the relationship between leverage and $\alpha_{i, t}$, the distribution of leverage also has a thicker right tail, and we can observe a significant growth in risk-taking (higher $\alpha_{i, t}$ ) in the run-up to the crisis (Figure 4 ). In recent years, this trend has reversed, and the right tail parameter has risen. We interpret an increase of the right tail parameter as reflecting the imposition of stricter regulatory policies,

\footnotetext{
${ }^{11}$ In Table A2 we can also observe that the period of 2000 - 2008 was characterized by a low right tail parameter when compared to both the preceding period $(1993-2000)$ and the post-crisis period of 2009 2018.
} 

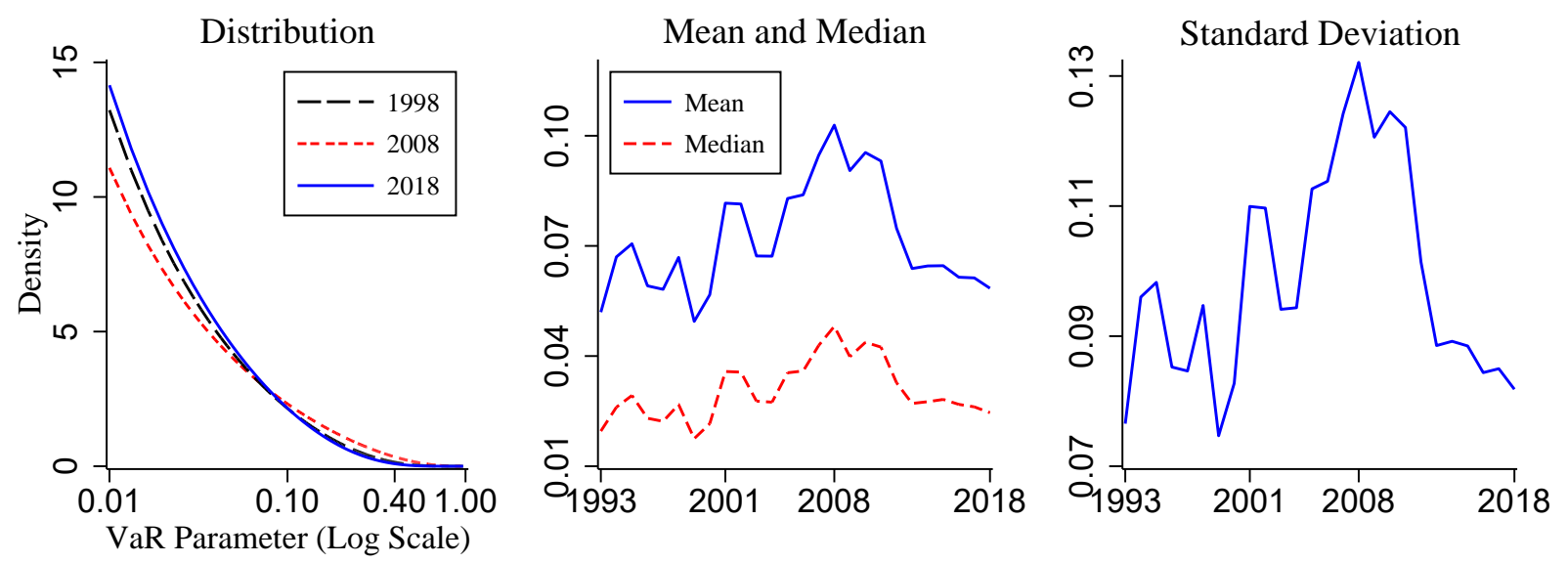

Figure 4: Estimated Distribution of Risk-Taking Behavior, $\alpha_{i, t}$ : The figure plots the estimated distribution of $\alpha_{i, t} \sim \phi_{c, t} \times \operatorname{Beta}\left(\phi_{L, t}, \phi_{R, t}\right)$ on $\left(0, \phi_{c, t}\right)$. In the first figure, the black long and red short dashed and blue solid lines are the estimated distribution based on parameter estimates for the years 1998, 2008, and 2018, respectively. In the second figure, the blue solid and red dashed lines report the mean and median, respectively. The third figure plots the standard deviation. The statistics are calculated from the estimated distributions as follows. The mean, median, standard deviations of the distribution $\alpha_{i, t}$ are $\phi_{c, t} \phi_{L, t} /\left(\phi_{L, t}+\phi_{R, t}\right)$ and $\phi_{c, t} I_{1 / 2}^{-1}\left(\phi_{L, t}, \phi_{R, t}\right)$, and $\phi_{c, t} \sqrt{\phi_{L, t} \phi_{R, t}} /\left[\left(\phi_{L, t}+\phi_{R, t}\right) \sqrt{\phi_{L, t}+\phi_{R, t}+1}\right]$, respectively, in which $I_{p}\left(\phi_{L, t}, \phi_{R, t}\right)$ is the regularized incomplete beta function.

ceteris paribus. Regulatory policies can be of a micro-prudential or a macroprudential nature and supervisors implement them with different degrees of tightness. While micro-prudential policies existed in most countries before the great financial crisis, macroprudential policies were virtually nonexistent in advanced economies before 2009. As a result, the $\phi_{R, t}$ parameter reflects the tightness of micro-prudential regulations before 2009 and the tightness of micro and macroprudential regulations after 2009. After the Great Financial Crisis, there was a regulatory tightening in response to the lax regulatory framework pre-crisis, seen as one of the causes of the crisis.

After initial responses during the crisis (such as the Emergency Economic Stabilization Act and the Federal Housing Finance Reform in 2008 in the US), the main change in banking regulation has been the enactment of macroprudential policies in advanced economies. As 
can be seen in Figure 3, the measure of macroprudential policy stance of Forbes $(2021)^{12}$ highlights how macroprudential policies were largely nonexistent in advanced economies before 2009. Macroprudential policies consist in particular of the imposition of countercyclical capital buffers, of maximum leverage ratios as well as liquidity coverage ratios. All these tools have an impact on the ability of intermediaries to take on risk, i.e., they should result in an increase in $\phi_{R, t}$ (the risk-taking distribution's right tail becoming thinner) as fewer intermediaries can now be very leveraged and take on much risk. These macroprudential measures were enacted in the European Union, the UK, Switzerland, Japan and with a bit of delay in the United States (although Dodd-Frank was signed into US law in 2010). The speed of adopting macroprudential policies in those jurisdictions is therefore well summed up by the advanced economy macroprudential stance of Forbes (2021)'s data. The highest risk-taking intermediaries in our sample are from the EU, UK, US, Swiss and Japanese banks (see panel B of Table A1), jurisdictions which are all affected by the tightening. Therefore we expect the tightening of macroprudential policies in advanced economies after 2009 to correlate positively with our estimated $\phi_{R, t}$. This is indeed the case as can be seen in Figure 3 .

Pre-2009, the regulatory policy stance is affected by changes in microprudential regulation. We use the timeline of Barth and Miller (2018) to identify the major regulatory changes during the sample period. We note one major pre-2009 regulatory change in our sample: the Gramm-Leach-Bliley Financial Services Modernization Act of 1999, which repealed the Glass-Steagall Act of 1933 and expanded the permissible scope of activities for bank holding companies and bank subsidiaries ${ }^{13}$. We would therefore expect a decrease in $\phi_{R, t}$ after 1999 (loosening of regulation). We observe this pattern in Figure 3 of the paper: the loosening after 1999 is quite clear. We also note that in 2000, the Commodity Futures Modernization Act removed credit default swaps and other over-the-counter derivative contracts from the

\footnotetext{
${ }^{12}$ We are very grateful to Kristin Forbes for sharing her data and calculations of the macroprudential policy stance.

${ }^{13}$ The Riegle-Neal Act of 1994 allowed adequately capitalized banks to branch across state lines while also removing restrictions on interstate mergers and acquisitions. On the other hand, Sarbanes-Oxley in 2002 improved transparency standards across US firms, including financial ones.
} 
regulatory jurisdiction of the Commodity Futures Trading Committee. In 2004, the Securities and Exchange Commission reduced the proportion of capital that investment banks have to hold in reserves. These two regulatory changes accentuated the ability of banks to take on risk and should therefore decrease $\phi_{R, t}{ }^{14}$

Basel 2 was negotiated in 2004, and the EU Parliament and Council adopted Basel 2 inspired regulation shortly thereafter. These were gradually transposed into different national laws mostly in 2007 (for example, Germany, Switzerland, UK) and 2008 (for example, France). The US adopted Basel 2 in 2008. Compared to Basel 1, in place since 1988, Basel 2 introduced more flexibility in the modeling of risk by banks to assess regulatory capital. From 2004, the Basel 2 process accelerated the adoption by large banks of new risk metrics such as the Internal Ratings Based approach (IRB). This enabled large banks to take what can ex-post be described as an optimizing attitude to risk modeling (optimizing internal risk models to minimize regulatory capital). This trend is plausibly reflected in the declining $\phi_{R, t}$ parameter between 2004 and 2008 reflecting, in particular, the large increase in leverage of EU banks (in 2008, 12 out of the 20 most risk-taking banks are EU or Swiss banks in our sample) ${ }^{15}$.

Hence, before 2009, we see the decline in $\phi_{R, t}$ as reflecting the effect of Gramm-Leach-Bliley after 1999 in the US and of banking integration and Basel 2 gradual implementation in Europe after 2004 in a context where supervisors were relatively "hands off" in a number of countries. Alan Greenspan (Fed Chairman until 2006) famously recognized in 2008 in front of a congressional committee that he had been wrong about the ability of banks and markets to self-regulate: "I made a mistake in presuming that the self-interests of organizations, specifically banks and others, were such that they were best capable of protecting their own shareholders and their equity in the firms"16. Similarly, the UK Financial Service Authority has been heavily criticized (and indeed got broken up) for its "light touch" approach to

\footnotetext{
${ }^{14}$ Because the US Dollar is an important currency in banking and global banks operate and refinance in part in US Dollars, US regulation tends to spillover to large non-US banks. See Gourinchas, Rey and Sauzet (2019) for the importance of US dollar as an international currency and Miranda-Agrippino and Rey (2020) for the effect of US funding costs on non-US bank leverage).

${ }^{15}$ See Vives (2000); Dermine (2006) for the European banking integration and deregulation

${ }^{16}$ https://www.nytimes.com/2008/10/24/business/economy/24panel.html
} 
regulation pre-2008. ${ }^{17}$ In that pre-2008 environment where the dominant supervision doctrine was one of "laissez-faire", banks could be stretching regulatory frameworks to their limits if they so wished. Some of them were increasing their leverage massively without any corresponding increase in their value-at-risk: leverage was going up over time while estimated risk-weighted capital stayed constant. This period of lax regulation and laissez-faire is captured by a decrease in the right tail parameter between 1999 and 2008. After the crisis, macroprudential regulations were gradually tightened in all advanced economies, supervisors became much more active, and our right tail parameter went back up.

Central to our estimation strategy are the intermediaries' VaR constraints, which are hard to get directly from the data ${ }^{18}$. Fitting the implied moments of risk-taking $\alpha_{i, t}$ and uncertainty (volatility) $\sigma_{Z, t}$, however, can serve as an indirect test of our empirical framework. We perform a number of external validation checks of our estimates. Figure 4 shows the estimated distribution of risk-taking behavior and some cross-sectional statistics over time. In the figure, the mean and median plots are inversely U-shaped. The peak of intermediaries' risk-taking, on average, is around the financial crisis, with a sustained rise between 1999 and 2008. This pattern corresponds to the U-shape of right-tail parameters over time in Figure 2. That pattern implies that the right tail movements mainly drive the distribution changes over time. In Figure 4, one can see that the right tail around 2008 is fatter than that of 2018 or 2013. Interestingly, we also see that the dispersion of risk-taking parameters is increasing markedly before the crisis. This fits very well with the papers cited in the introduction, which emphasize a race for a market share of the most reckless financial intermediaries during boom times, while the most conservative ones hold back. Understanding the time variations in the distribution of risk-taking parameters is important because they are systemically related to financial instability in the macroeconomy.

To check our model's validity, we also look at whether the secular trends in our implied

\footnotetext{
${ }^{17}$ https://www.theguardian.com/business/2009/feb/26/regulators

${ }^{18}$ Some large banks report some of their VaRs. However, they do not cover their entire balance sheet, and because they depend on internal risk models for specific portfolios, they could misrepresent the overall risk-taking behavior of intermediaries.
} 


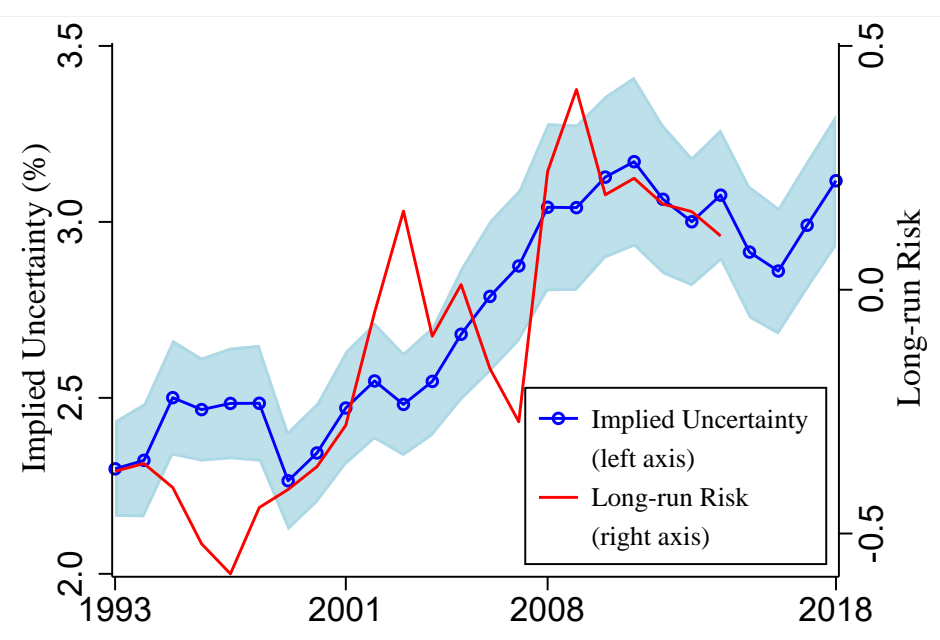

Figure 5: Uncertainty: The figure plots implied uncertainty $(\%) 100 \times \sigma_{Z, t}=100 \times \pi /\left(\phi_{p, t} \sqrt{3}\right)$ from the estimation results (blue line with circles) with $95 \%$ intervals (light blue shades) and long-run risk measure (red line) as an uncertainty measure. The long-run risk measure comes from Schorfheide, Song and Yaron (2018)'s structural model estimation.

uncertainty measure are consistent with traditional measures in the literature. Figure 5 illustrates estimates for uncertainty in asset returns derived from our structural model as $\sigma_{Z, t}=\pi /\left(\phi_{p, t} \sqrt{3}\right)$. We find an increasing secular trend of implied uncertainty, up to the financial crisis, with a slight reversion in its aftermath. Even though we do not use any standard macro variables and extract information only from the cross-sectional moments of leverage alongside our structural model, the implied uncertainty of the economy shows a similar pattern to the macroeconomic risk of long-term economic growth estimated by Schorfheide, Song and Yaron (2018): i.e., the volatility of the persistent component in the long-run risk model. Comin and Philippon (2005); Kehrig (2015); Bloom et al. (2018); Farhi and Gourio (2018); Schorfheide, Song and Yaron (2018) document similar patterns of rising volatility or uncertainty in macro and macro-finance. ${ }^{19}$

\footnotetext{
${ }^{19}$ More precisely, our implied uncertainty changes are consistent with 1) Farhi and Gourio (2018)'s risk component of the spread between the marginal product of capital and the risk-free rates, 2) Schorfheide, Song and Yaron (2018)'s estimate of long-run risk components, 3) Comin and Philippon (2005); Kehrig (2015); Bloom et al. (2018) document a similar pattern of (respectively) rising volatility, dispersion and uncertainty in macro.
} 
Table 1: Risk-Taking Behavior: Distressed or Defaulted Banks during 2007 - 2009

\begin{tabular}{lccccc}
\hline & Full Sample & \multicolumn{2}{c}{ Sub-sample } \\
\cline { 4 - 5 } & & Default & \multicolumn{2}{c}{ Distress } \\
\cline { 5 - 6 } Statistics & & & 0.462 & 0.152 & 0.310 \\
\hline VaR parameter & Mean & 0.125 & 0.730 & 0.197 & 0.547 \\
Upper quantile (P75) & 0.135 & 0.547 & 0.045 & 0.245 \\
Median & (P50) & 0.043 & 0.195 & 0.010 & 0.010 \\
Lower quantile (P25) & 0.009 & 11 & 427 & 55 \\
\hline Observations & 1326 & & &
\end{tabular}

\section{Risk-Taking and Economic Performance}

\subsection{Risk-Taking Behavior and Financial Distress}

To provide external validation of our estimates, we now study the link between estimated VaR parameters and outcomes. The VaR parameter should have a strong link with the intermediary's risk-taking and, therefore, its economic performance. More precisely, the estimated VaR parameter should strongly predict the (ex-post) default or distress of individual financial intermediaries. We check whether our measure predicts bank outcomes, despite not using any specific information about those in our estimation procedure.

As equation (5) highlights, the VaR parameter is the probability that returns on equity are negative. A negative RoE may lead to default, liquidation, delisting, and/or being acquired. We construct a default dummy De fault $t_{i, t}$ using a strict definition of default ${ }^{20}$. We also construct a distress event dummy Distress $i_{i, t}$ using combinations of the following events: (1) income is non-positive, (2) equity becomes non-positive, and (3) existed in the previous period but is no longer available in the current period. The benchmark distress dummy Distress $s_{i, t}$ has value one if (1), (2), or (3) occurs at time $t+1$, and 0 otherwise. As an alternative, we also consider (2) and (3) for a more narrowly defined distress event. ${ }^{21}$

\footnotetext{
${ }^{20}$ When Research Company Reason for Deletion $\left(\mathrm{dl}_{\mathbf{r s n}}\right)$ is identified as 02 (Bankruptcy) or 03 (Liquidation). This definition is, however, very limited because of missing labels in the data. In our sample, only $0.1 \%$ of banks are identified explicitly as bankrupt or liquidated, which is significantly lower than what can be inferred from FDIC data.

${ }^{21}$ More precisely, in the benchmark, Distress $s_{i, t}=1$ when the following cases occur: (1) Income is nonpositive: $i b_{i, t+1} \leq 0,(2)$ Research Company Deletion Date is non-empty dldte $e_{i} \neq \cdot$, and $t$ is the last period
} 
Table 2: Risk-Taking Behavior and Bank Distress

\begin{tabular}{|c|c|c|c|c|c|c|c|c|}
\hline & \multicolumn{8}{|c|}{ Distress Dummy: Distress ${ }_{i, t}$} \\
\hline & \multicolumn{4}{|c|}{ Benchmark Broad Definition } & \multicolumn{4}{|c|}{ Alternative Narrow Definition } \\
\hline & (1) & (2) & (3) & (4) & $(5)$ & (6) & (7) & (8) \\
\hline VaR parameter & $\begin{array}{c}0.09^{* *} \\
(0.03)\end{array}$ & $\begin{array}{c}0.23^{* * *} \\
(0.01)\end{array}$ & $\begin{array}{l}0.13^{* *} \\
(0.05)\end{array}$ & $\begin{array}{c}0.19^{* * *} \\
(0.01)\end{array}$ & $\begin{array}{c}0.04 \\
(0.04)\end{array}$ & $\begin{array}{c}0.16^{* * *} \\
(0.02)\end{array}$ & $\begin{array}{l}0.11^{* *} \\
(0.05)\end{array}$ & $\begin{array}{c}0.15^{* * *} \\
(0.02)\end{array}$ \\
\hline Other Controls & Yes & Yes & Yes & Yes & Yes & Yes & Yes & Yes \\
\hline Bank FE & No & No & Yes & Yes & No & No & Yes & Yes \\
\hline Year FE & Yes & No & Yes & No & Yes & No & Yes & No \\
\hline Year-Bank Type FE & No & Yes & No & Yes & No & Yes & No & Yes \\
\hline Year-Country FE & No & Yes & No & Yes & No & Yes & No & Yes \\
\hline Observations & 7417 & 7164 & 7362 & 7109 & 7417 & 7164 & 7362 & 7109 \\
\hline R-squared & 0.11 & 0.16 & 0.28 & 0.31 & 0.02 & 0.04 & 0.21 & 0.22 \\
\hline
\end{tabular}

Note: ${ }^{*} p<0.1,{ }^{* *} p<0.05,{ }^{* * *} p<0.01$. Standard errors (in parentheses) are clustered at the country-bank type level. Singleton observations are dropped in all regressions. The estimation is based on equation (6). We use a logistic estimation. The dependent variable is the one-year ahead distress dummy. Other controls are dividend yield, book to market ratio, and asset size in logs.

Table 1 shows some summary statistics for quantiles values of the estimated VaR parameter around the global financial crisis. The subset of banks that defaulted or were in distress indeed have significantly larger estimated risk-taking parameters than the population and that this difference is larger, the stricter the definition is. This comforts us in the view that our estimated distributions capture risk-taking meaningfully.

For an investigation of the statistical relation between VaR parameters and realized distress events ${ }^{22}$, we estimate the following logistic regression equation:

$$
\text { Distress }_{i, t}=b_{0}+b_{1} \alpha_{i, t}+\left(\ln \mathbf{x}_{i, t}\right)^{\mathrm{T}} \mathbf{b}+\delta_{i, t}+\varepsilon_{i, t}
$$

The bank corporate trait vector is denoted by $\mathbf{x}_{i, t}$ and includes dividend yield, book to market ratio, and asset size. Note that our regressions also include various fixed effects denoted broadly by $\delta_{i, t}$. We include a bank, bank type, country, and/or year fixed effects. ${ }^{23}$ of $i$ 's observations, (3) Assets at $t_{i, t+1}$ are not greater than total liabilities $1 t_{i, t+1}$, (4) Negative Stockholders' Equity - Total is non-positive: $\mathbf{s e q}_{i, t+1} \leq 0,(5)$ Negative Common/Ordinary Equity — Total is non-positive: $\mathrm{ceq}_{i, t+1} \leq 0$, or $(6)$ Common Equity - Tangible is non-positive: ceqt $_{i, t+1} \leq 0$. The alternative distress dummy Distress alt $=1$ when at least one of $(2)-(5)$ or (6) occurs.

${ }^{22}$ There are not enough default observations to run a regression.

${ }^{23}$ We use the North American Industry Classification System (NAICS) 4 digit code for bank type. 

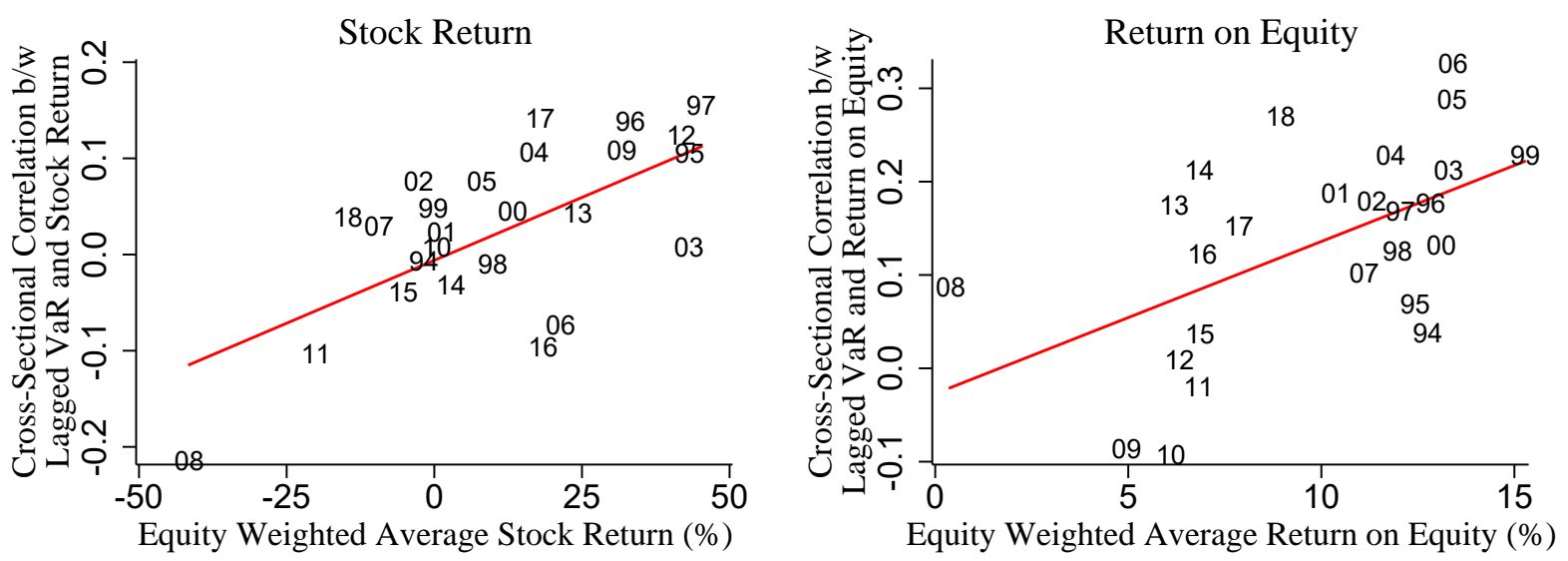

Figure 6: Risk-Taking Behavior and Bank Performance: The figures plot each year crosssectional correlation between a bank's lagged risk-taking measure $\left(\alpha_{i, t}\right)$ and its performance measure (the y-axis) and each period average performance of banks weighted by the equity (the $\mathrm{x}$-axis). Bank performance is measured by stock returns (left) and return on equity (right). See Figure A6 for the corresponding figure with return on asset.

These fixed effects allow us to control for (i) any time-invariant firm-specific, sub-sector, and cross-country differences that might affect the distress and (ii) time-varying characteristics that influence the distress.

Table 2 provides statistically significant evidence on the positive association of our risk-taking measure (VaR parameter) with ex-post bank distress. Our VaR parameter is consistently positively associated with a higher probability of distress for all our specifications. We now look at whether the pattern of stock returns is also consistent with our structural model.

\subsection{Risk-Taking Behavior and Stock Returns}

Conventional theory suggests that high risk-taking intermediaries' ex-post returns should be larger in good times, but that their losses should be larger in bad times (see MirandaAgrippino and Rey, 2020). We now use the estimated risk-taking behavior in the previous section to predict stock returns during good and bad times in order to provide further evidence on the external validity of our estimates. 
Figure 6 highlights that the cross-sectional correlation between the lagged VaR parameter and bank performance (measured by stock returns or return on equity) fluctuates over time. This is because the relationship between intermediary risk-taking and performance depends on the banking sector's aggregate performance. When the banking sector performs well, high risk-taking intermediaries earn more than others, thus profiting from their aggressive approach. The cross-sectional correlation between lagged VaR and returns is then positive. However, when returns are negative, they also make the largest losses, and the correlation turns negative.

To examine whether bank's risk-taking behavior matters for stock returns more formally, we use the following panel regression:

$$
r_{i, t+1}^{\text {excess }}=b_{0}+b_{1} \ln \alpha_{i, t}+\left(\ln \mathbf{x}_{i, t}\right)^{\mathrm{T}} \mathbf{b}+\delta_{i, t}+\varepsilon_{i, t}
$$

which predicts one-year forward excess stock return (\%) $r_{i, t+1}^{\text {excess }}$ defined by a bank $i$ 's stock returns $r_{i, t+1}^{\text {stock }}$ minus the equity-weighted average stock return $\bar{r}_{t+1}^{\text {stock }}$, conditional on the risktaking behavior (VaR parameter $\alpha_{i, t}$ ) in logs, other controls and fixed effects. The bank corporate trait vector is denoted by $\mathbf{x}_{i, t}$ and includes dividend yield, book to market ratio, and asset size. Our regression also includes various fixed effects denoted by $\delta_{i, t}$. We include a bank, year-bank type, and/or year-country fixed effects. ${ }^{24}$ These fixed effects allow us to control (i) any time-invariant financial intermediaries' characteristics that generate a firm-specific trend in stock returns, (ii) any time-varying and time-invariant sub-sector differences that might affect stock returns, and (iii) time-varying and time-invariant country characteristics that influence the stock market performances.

In Table 3, we present the results of the panel regression model specified in equation (7) using three different samples. ${ }^{25}$ Columns (1), (4), and (7) correspond to results associated

\footnotetext{
${ }^{24}$ The North American Industry Classification System (NAICS) 4 digit code classifies our bank type.

${ }^{25}$ Table A3 reports additional estimation results. We split the sample between "bull" and "bear" periods based on the equity-weighted average of market returns $\bar{r}_{t+1}^{\text {stock }}$. The bull and bear markets are $\bar{r}_{t+1}^{\text {stock }}>0$ and $\leq 0$, respectively.
} 
Table 3: Risk-Taking Behavior and Stock Returns

\begin{tabular}{lcccccccccc}
\hline & \multicolumn{7}{c}{ One Year Ahead Excess Stock Returns: $r_{i, t+1}^{\text {excess }}=r_{i, t+1}^{\text {stock }}-\bar{r}_{t+1}^{\text {stock }}$} \\
\cline { 2 - 10 } Sample & $(1)$ & $(2)$ & $(3)$ & $(4)$ & $(5)$ & $(6)$ & $(7)$ & $(8)$ & $(9)$ \\
& All & Positive & Negative & All & Positive & Negative & All & Positive & Negative \\
\hline VaR parameter $(\log )$ & $0.71^{* * *}$ & $1.23^{* * *}$ & $-0.23^{* *}$ & $1.64^{* * *}$ & $2.03^{* * *}$ & $-0.49^{* * *}$ & $1.64^{* * *}$ & $1.96^{* * *}$ & $-0.55^{* * *}$ \\
& $(0.20)$ & $(0.21)$ & $(0.09)$ & $(0.26)$ & $(0.09)$ & $(0.12)$ & $(0.26)$ & $(0.03)$ & $(0.04)$ \\
& & & & & & & & & \\
\hline Other Controls & No & No & No & Yes & Yes & Yes & Yes & Yes & Yes \\
Bank FE & Yes & Yes & Yes & Yes & Yes & Yes & Yes & Yes & Yes \\
Year FE & Yes & Yes & Yes & Yes & Yes & Yes & No & No & No \\
Year-Bank Type FE & No & No & No & No & No & No & Yes & Yes & Yes \\
Year-Country FE & No & No & No & No & No & No & Yes & Yes & Yes \\
Observations & 8260 & 5421 & 2692 & 6986 & 4554 & 2304 & 6986 & 4376 & 2177 \\
R-squared & 0.24 & 0.38 & 0.70 & 0.36 & 0.50 & 0.73 & 0.36 & 0.56 & 0.75 \\
\hline
\end{tabular}

Note: ${ }^{*} p<0.1,{ }^{* *} p<0.05,{ }^{* * *} p<0.01$. Standard errors (in parentheses) are clustered at the country-bank type level. Singleton observations are dropped in all regressions. The estimation is based on equation (7). The dependent variable is the excess stock return. Other controls are dividend yield, book to market ratio, and asset size in logs. Columns (2), (5), and (8) only include intermediaries with positive excess market returns. Columns (3), (6), and (9) only include intermediaries with negative excess market returns.

with the entire sample. Intermediary market returns increase when they take more risk. When an intermediary's VaR threshold parameter increases one basis point, its stock return increases between $0.71 \%$ and $1.64 \%$. Risk-taking is, on average, compensated by larger returns, as expected. We also consider the following two subsamples. In Columns (2), (5), and (8), we first include intermediaries with positive excess market returns. Second, Columns (3), (6), and (9) contain intermediaries with negative excess market returns. When intermediaries succeed, their market returns are increasing in risk-taking. However, their returns are decreasing in risk-taking when they fail.

Figure 6 provides descriptive evidence supporting the prediction that high risk-taking financial intermediaries lose more than others if bad states occur. In Table 4, we test this hypothesis by interacting the estimated risk-taking behavior $\ln \alpha_{i, t}$ with dummies indicating financial crises at $t+1$ in regression equation (7). As expected, the estimated coefficients of the interaction term are significantly negative. Risk-taking predicts excess returns but also larger volatility of returns and their pattern over the business cycle. All this is consistent with the conventional view of risk-taking and returns. Note that even though we did not use 
Table 4: Risk-Taking Behavior and Stock Returns during Crises

\begin{tabular}{|c|c|c|c|c|c|c|}
\hline & \multicolumn{6}{|c|}{ One Year Ahead Excess Stock Returns: $r_{i, t+1}^{\text {excess }}=r_{i, t+1}^{\text {stock }}-\bar{r}_{t+1}^{\text {stock }}$} \\
\hline & (1) & $(2)$ & $(3)$ & (4) & (5) & (6) \\
\hline VaR parameter $(\log )$ & $\begin{array}{c}0.75^{* * *} \\
(0.07)\end{array}$ & $\begin{array}{c}1.84^{* * *} \\
(0.29)\end{array}$ & $\begin{array}{c}1.56^{* * *} \\
(0.02)\end{array}$ & $\begin{array}{c}0.79^{* * *} \\
(0.07)\end{array}$ & $\begin{array}{c}1.80^{* * *} \\
(0.28)\end{array}$ & $\begin{array}{c}1.52^{* * *} \\
(0.02)\end{array}$ \\
\hline \multicolumn{7}{|c|}{ VaR parameter $(\log ) \times$ Crisis Dummy $($ One-Year Ahead $)$} \\
\hline Global Financial Crisis (2008) & $\begin{array}{c}-4.49^{* * *} \\
(0.34)\end{array}$ & $\begin{array}{c}-3.24^{* * *} \\
(0.49)\end{array}$ & $\begin{array}{r}-2.74^{* * *} \\
(0.02)\end{array}$ & & & \\
\hline $\begin{array}{l}\text { Global Financial Crisis (2008) } \\
\text { and Sovereign Debt Crisis (2011) }\end{array}$ & & & & $\begin{array}{c}-3.69^{* * *} \\
(0.28)\end{array}$ & $\begin{array}{c}-2.05^{* * *} \\
(0.44)\end{array}$ & $\begin{array}{c}-1.69^{* * *} \\
(0.02)\end{array}$ \\
\hline Other Controls & Yes & Yes & Yes & Yes & Yes & Yes \\
\hline Bank FE & No & Yes & Yes & No & Yes & Yes \\
\hline Year FE & Yes & Yes & No & Yes & Yes & No \\
\hline Year-Bank Type FE & No & No & Yes & No & No & Yes \\
\hline Year-Country FE & No & No & Yes & No & No & Yes \\
\hline Observations & 7042 & 6986 & 6736 & 7042 & 6986 & 6736 \\
\hline R-squared & 0.03 & 0.36 & 0.47 & 0.03 & 0.36 & 0.46 \\
\hline
\end{tabular}

Note: ${ }^{*} p<0.1,{ }^{* *} p<0.05,{ }^{* * *} p<0.01$. Standard errors (in parentheses) are clustered at country-bank type level. Singleton observations are dropped in all regressions. The estimation is based on equation (7). The dependent variable is the excess stock return. Other controls are dividend yield, book to market ratio, and asset size in logs.

any information on returns or additional business cycle variables to estimate $\alpha_{i}$, our measures predict patterns consistent with our structural interpretation based on risk-taking.

\section{Systemic Risk and Concentration of Risk}

In this section, we use our structural measures of risk-taking to generate a simple aggregate measure that is indicative of risk in the financial sector as a whole. We depart from our individual measures of risk-taking, and although we could, in practice, use information from the entire set of moments of the distribution, we take a simple approach and provide a scalar index of systemic risk. To do so, we simply weigh the risk-taking parameter of each intermediary by its balance sheet size. Intuitively this corresponds to the ex-ante probability that a certain proportion of assets are in the hands of distressed intermediaries.

Using equation (5), observed leverage $\lambda_{i, t}$ and the set of estimated parameters $\hat{\Psi}_{t}$, we can recover the implied empirical distribution of $\hat{\alpha}_{i, t}$ and calculate measures of systemic risk 

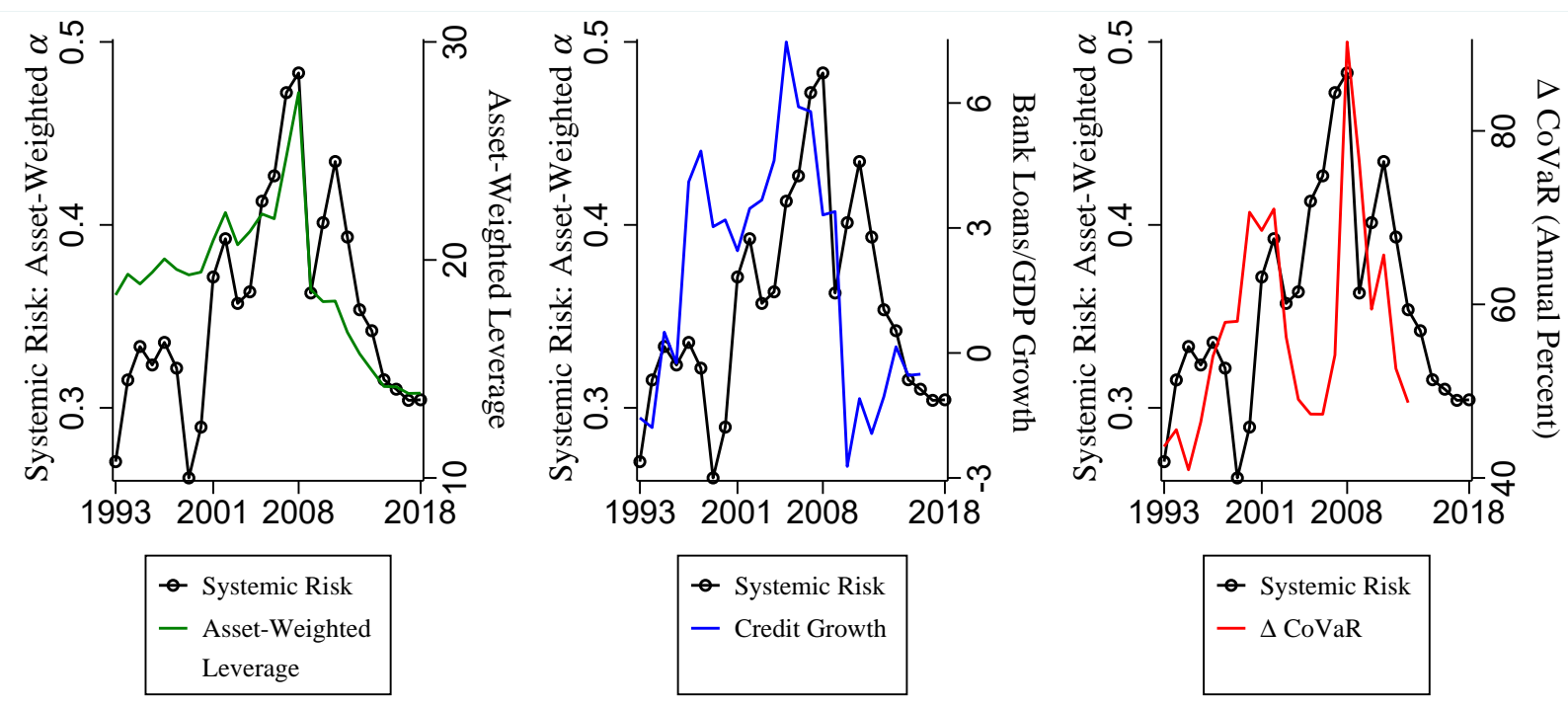

Figure 7: Evolution of Systemic Risk over Time, $\bar{\alpha}_{t}^{A W}$ : The figures plot the systemic risk measured by the estimated asset-weighted VaR parameter (black circled lines) and alternative measures (solid lines) from previous studies. In the left figure, the green line (right y-axis) is the asset-weighted leverage in our sample. In the middle figure, the blue line (right y-axis) is the bank credit measured by the sum of the country's total loans to the non-financial private sector divided by the sum of each country's GDP (nominal, USD). Then, we calculate the growth rates. The data are from the Jorda-Schularick-Taylor Macrohistory Database. In the right figure, the red line (right $\mathrm{y}$-axis) is $\Delta \mathrm{CoVaR}$, the change in the value-at-risk of the financial system conditional on an institution being under distress relative to its median state, from Adrian and Brunnermeier (2016). We calculate the annual $\Delta \mathrm{CoVaR}$ by adding their quarterly $\Delta \mathrm{CoVaR}$ (estimated using data $1971-$ 2013) each year.

such as $\bar{\alpha}_{t}^{A W}$, the asset-weighted mean of VaR parameters. We can of course also recover the unweighted averages $\bar{\alpha}_{t}^{U}$, although we believe it is important to weigh the risk-taking parameter by the economic size of the respective intermediary. Specifically:

$$
\bar{\alpha}_{t}^{A W} \equiv \sum_{i=1}^{N_{t}}\left(\frac{a_{i, t}}{\sum_{j=1}^{N_{t}} a_{j, t}}\right) \hat{\alpha}_{i, t} \quad \text { and } \quad \bar{\alpha}_{t}^{U} \equiv \frac{1}{N_{t}} \sum_{i=1}^{N_{t}} \hat{\alpha}_{i, t}
$$

where $N_{t}$ is the number of financial intermediaries and $a_{i, t}$ the balance sheet size of intermediary $i$ at time $t$.

Our benchmark measure of systemic risk is the asset-weighted mean of risk-taking $\bar{\alpha}_{t}^{A W}$, which takes into account the size of each intermediary in the macroeconomy. For example, an economy with one safe and one very risky intermediary will not have the same amount of 
macroeconomic risk if the risky bank only holds $5 \%$ of assets or holds $95 \%$ of the assets. A nice feature of our framework is that we have a direct mapping between the underlying parameters of our VaR framework and different relevant definitions of systemic risk such as "ex-ante probability that a certain percentage of assets are in the hands of distressed intermediaries" or "ex-ante probability that the entire leverage sector (or $\mathrm{x} \%$ of it) is distressed".

In Figure 7, we present the time series of the asset-weighted mean of estimated risk-taking $\bar{\alpha}_{t}^{A W}$ which is the asset-weighted (ex-ante) probability of distress (VaR parameter) of the entire sample of intermediaries. ${ }^{26}$ We compare it in each panel to an alternative measure of systemic risk taken from the literature. We estimate $\bar{\alpha}_{t}^{A W}$ from the Compustat Fundamentals Annual data using the methodology described above. As is clear from the figure, our estimates suggest a significant increase in systemic risk between 2000 and 2008 as liquidity conditions in the global economy were loose and regulations were lax, and a significant decline after 2008 and as banking regulations tightened. In the next section, we provide counterfactual exercises in which we explore further these different factors.

Figure 7 also compares our measure to three different alternatives. In the left panel, we compare it to a simple asset-weighted mean of leverage. This illustrates the usefulness of the structural model, as asset-weighted leverage completely misses the increased systemic risk during the European sovereign debt crisis and seems to be relatively flat almost until 2008 when the crisis actually hits. This delayed rise is also there to an even greater extent with the $\Delta \mathrm{CoVaR}$ measure, which dramatically rises in 2008 but gave no early warning signs to a policymaker observing the measure in the preceding years. This is a common problem with price-based measures: when they predict a crisis, it is too late. Credit growth (middle panel) seems to exhibit the most similar pattern to our measure, but it would also miss the

\footnotetext{
${ }^{26}$ To check the impact of intermediary entry and exit, we consider a sub-sample consisting of continuing intermediaries. Based on the sub-sample, we re-estimate our parameters and compute each intermediary's risk-taking behavior parameter $(\alpha)$. We then re-calculate the systemic risk measure (asset-weighted $\alpha$ ). Figure A8 plots the estimated systemic risk measure using our benchmark database compared with the sub-sample of continuing financial intermediaries (i.e., at time $t$, all that are present also at $t-1$ and $t+1$ ). Both measures tightly comove and are quantitatively similar. We conclude that the changing sample has no systematic impact on our estimates and measures.
} 
European sovereign debt crisis and peak a couple of years before the crisis.

In order to explore further the role of heterogeneity in risk-taking across intermediaries we decompose our systemic risk measure $\bar{\alpha}_{t}^{A W}$ into a representative average component and an heterogeneous component. Using the definition of leverage, we express assets as $a_{i, t}=\lambda_{i, t} \omega_{i, t}$, and decompose the measure of systemic risk $\bar{\alpha}_{t}^{A W}$ around a reference point $\bar{\alpha}_{t}$ as follows:

$$
\bar{\alpha}_{t}^{A W}=\underbrace{\bar{\alpha}_{t} \lambda\left(\bar{\alpha}_{t} \mid \hat{\Phi}_{t}\right)\left(\frac{\sum_{j=1}^{N_{t}} \omega_{i, t}}{\sum_{j=1}^{N_{t}} a_{j, t}}\right)}_{\text {average component }}+\underbrace{\sum_{i=1}^{N_{t}}\left[\hat{\alpha}_{i, t} \lambda_{i, t}-\bar{\alpha}_{t} \lambda\left(\bar{\alpha}_{t} \mid \hat{\Phi}_{t}\right)\right]\left(\frac{\omega_{i, t}}{\sum_{j=1}^{N_{t}} a_{j, t}}\right)}_{\text {heterogeneity component }},
$$

where $\lambda\left(\alpha \mid \Phi_{t}\right)=\left\{1-\phi_{s, t}\left(\phi_{c, t}\right)^{-1 / \phi_{p, t}}[\alpha /(1-\alpha)]^{1 / \phi_{p, t}}\right\}^{-1}$ is derived from equation (5). The average component takes the unweighted average of intermediaries' risk-taking behavior $\bar{\alpha}_{t}=\bar{\alpha}_{t}^{U}$ as its reference point. ${ }^{27}$ Here, the first and second components represent the contribution of average and heterogeneous financial intermediaries, respectively. Intuitively, the average component considers the risk-taking of a representative intermediary with mean risk-taking, while the heterogeneity component is the sum of the additional contributions arising from the deviations of each intermediary from the representative agent's behavior.

Figure 8 highlights the importance of heterogeneous financial intermediaries in macrofinance research. The first panel of Figure 8 shows that the average component plays a limited role in the fluctuations of our systemic risk measure, though it accounts for about $28.6 \%$ of the measure on average. ${ }^{28}$. However, the heterogeneous component drives the vast majority of the dynamics and peaks exactly around the crisis, while the average component peak would happen post-crisis and even seems to fall slightly in the run-up to the crisis. The correlation coefficients of the systemic risk measure with the average and heterogeneous terms are 0.390 and 0.991, respectively. Considering heterogeneity is therefore extremely important, not only in the estimation procedure but also for the dynamics and level of the systemic risk measure.

\footnotetext{
${ }^{27}$ Alternatively, we can decompose the systemic risk measure as $\bar{\alpha}_{t}^{A W}=\bar{\alpha}_{t}+\sum_{i=1}^{N_{t}}\left(\hat{\alpha}_{i, t}-\bar{\alpha}_{t}\right)\left[a_{i, t} /\left(\sum_{j=1}^{N_{t}} a_{j, t}\right)\right]$, which does not yield significant difference from our decomposition in equation (8).

${ }^{28}$ The maximum and minimum share of the average component are 24.7 and $33.7 \%$, respectively.
} 

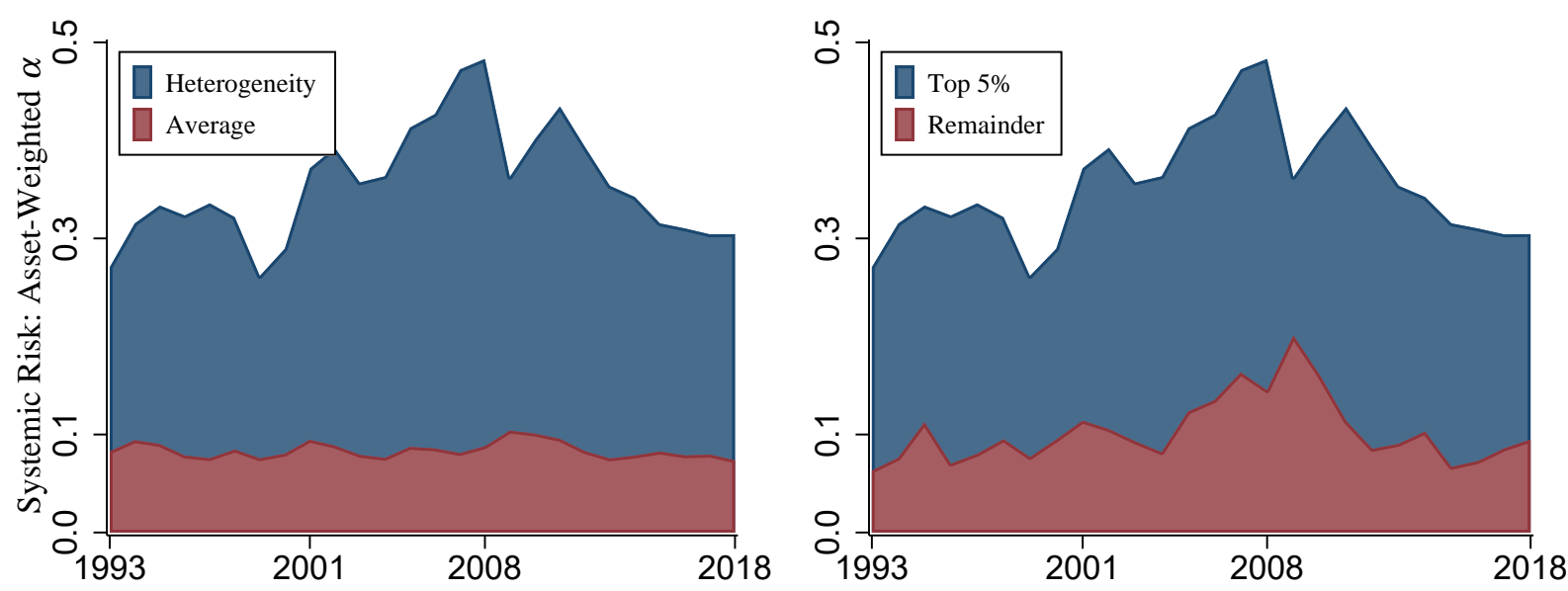

Figure 8: Heterogeneity and Concentration of Systemic Risk: The first figure plots the decomposition of systemic risk into the contributions of heterogeneity (blue) and average (red) components. The second figure plots the contributions of top $5 \%$ quantiles of the financial intermediaries' risk-taking behavior, $\alpha_{i, t}$, (blue) and the remainder (red).

The right panel of Figure 8 illustrates the concentration of risk and its changes over time, showing the time series of systemic risk for the top $5 \%$ quantile of risk-taking behavior, $\alpha_{i, t}$. The top $5 \%$ of intermediaries contribute to $71.0 \%$ of systemic risk over the sample. ${ }^{29}$ Moreover, high quantiles are positively correlated with the aggregate systemic risk measure. The correlation coefficient between aggregate systemic risk and contributions of the top 5\% is 0.817 . The peak of the contribution of the lower $95 \%$ occurs in the aftermath of the crisis, while the top $5 \%$ peaks in 2008. In Panel B of Table A1 we list the 20 institutions with the largest asset-weighted $\alpha$ in 2008 and their respective values in 2006 and 2010. These intermediaries, whether investment banks or universal banks, were highly levered and featured very large balance sheets before the crisis. This highlights the disturbing fact that several systemically important banks were engaging in significant risk-taking before the crisis.

It is clear that risk-taking does not rise and fall across the board, but that important cross-sectional patterns would be missed by simply looking at averages or aggregate variables. Modeling and tracking heterogeneity in the financial sector is important as financial instability

\footnotetext{
${ }^{29}$ The maximum and minimum share of the top $5 \%$ quantile contribution are 44.6 and $78.8 \%$, respectively.
} 
often arises from large, high risk-taking intermediaries.

\section{Counterfactual Analysis: Central Bank Policy}

This section presents two counterfactual exercises that provide insight into the impact of banking regulation and monetary policy (cost of funds) on financial instability and their contribution to our systemic risk measure dynamics.

In the first, we perform a counterfactual exercise on the tightness of financial regulation by fixing the right tail parameter $\phi_{R, t}$ of our risk-taking distribution. ${ }^{30}$ Since regulatory policy imposes limits to the risk-taking of intermediaries, it is natural to model changes in regulatory policy by changes in the right tail parameter as it describes the behavior of the riskiest players. A cap on leverage, for example, would affect the right tail parameter. Section 3 provides a further discussion on the link between regulatory changes and the observed variation in the estimated right tail parameter. We estimate the extent to which increases in regulatory tightness affect the degree of systemic risk.

For our second exercise, we calculate counterfactual systemic risk measures by changing the value of the ratio of expected returns on assets to the costs of funds $\zeta_{t} .{ }^{31}$ In Coimbra and Rey (2020), an expansionary monetary policy (low policy rate) directly lowers the cost of funds but also compresses spreads through its impact on asset prices. The spread parameter $\hat{\zeta}_{t}$ is the ratio of the expected rate of return of the risky asset and the risk-free rate and is, therefore, a measure of the risk premium. In the structural model of Coimbra and Rey (2020), the risk premium comoves positively with the monetary policy stance, and therefore

\footnotetext{
${ }^{30}$ As an alternative exercise, we could also fix both the left and right tail parameters. Because variations in the left tail shape are small, this exercise would yield close to our benchmark counterfactual analysis with the fixed right tail. Our counterfactual results with fixed $\phi_{R, t}$ and fixed $\left(\phi_{L, t}, \phi_{R, t}\right)$ are indistinguishable. Given our interpretation of regulation compressing the top tier of risk-taking, it seems natural to conduct our counterfactual analysis on changes in $\phi_{R, t}$.

${ }^{31}$ The estimated ratio of expected asset returns to funding costs consists of three estimates: $\hat{\zeta}_{t}=$ $\hat{\phi}_{s, t}\left(\hat{\phi}_{c, t}\right)^{-1 / \hat{\phi}_{p, t}}$. Note that $\hat{\phi}_{c, t}$ and $-1 / \hat{\phi}_{p, t}$ are close to one and zero, respectively: 0.99 and -0.01 on average between 1993 and 2018. Thus, $\hat{\phi}_{s, t}$ is the main driver of changes in $\hat{\zeta}_{t}$ over time. The power parameter $\phi_{p, t}$ is the mirror image of uncertainty: $\sigma_{Z, t}=\pi /\left(\phi_{p, t} \sqrt{3}\right)$. The scale parameter $\phi_{s, t}$ is the upper bound of risk-taking behavior: $\alpha_{t}^{\mathrm{ub}}=\phi_{s, t}$. We set the scale parameter for the counterfactual exercise to be $\tilde{\phi}_{s, t}=\tilde{\zeta}\left(\hat{\phi}_{c, t}\right)^{1 / \hat{\phi}_{p, t}}$ for given $\tilde{\zeta}$ and estimated $\hat{\phi}_{p, t}$ and $\hat{\phi}_{c, t}$.
} 
spreads are compressed when monetary policy is loose and vice-versa. In the model, the elasticity of banks' leverage with respect to the risk-free rate is stronger for more risk-taking intermediaries. Hence, when the cost of funds goes down, this concentrates assets in the hands of the more risk-taking banks, which drives risky returns down. This effect is stronger than the fall of the risk-free rate because of limited liability and the option value of default it generates. This option value comoves positively with leverage and further increases the attractiveness of risky assets leading to a fall in the risk premium. This risk-taking channel of monetary policy is documented in a number of papers (see Drechsler, Savov and Schnabl, 2017). Jimenez et al. (2014) show that credit by riskier banks is more elastic to monetary policy shocks. Dell'Ariccia, Laeven and Suarez (2017) similarly show that the response of loan supply is stronger for ex-ante more risk-taking banks. Altavilla et al. (2020) show the existence of a risk-taking channel and how it interacts with regulation. Importantly, in the data, there is direct evidence of the causal effect of monetary policy on risk premia (i.e., a loosening of monetary policy leads to a decrease in the risk premium and to a decrease in credit spreads whether measured by mortgage spreads or corporate spreads). This has been shown using high frequency identification for monetary policy shocks by a number of recent papers including Gertler and Karadi (2015), Miranda-Agrippino and Rey (2020) and Gerko and Rey (2017). Thus, our second counterfactual exercise allows us to investigate the contribution of monetary policy to the evolution of systemic risk.

The counterfactual systemic risk measures are straightforward to calculate:

- Step 0: Set the counterfactual parameter: $\tilde{\Phi}_{t} \cdot{ }^{32}$

- Step 1: Recover the the risk-taking behavior (VaR parameter) from the estimates of the distribution and leverage data: $\hat{\alpha}_{i, t}=\alpha\left(\lambda_{i, t} \mid \hat{\Phi}_{t}\right)$.

- Step 2: Use the complementary distribution function (tail distribution function) denoted by $\operatorname{codf}_{\alpha}\left(\cdot \mid \Phi_{t}\right)$ and its inverse function to calculate the implied counterfactual

\footnotetext{
${ }^{32}$ For example, we consider $\hat{\Phi}_{t}$ and $\tilde{\Phi}_{t}=\left\{\hat{\phi}_{p, t}, \hat{\phi}_{s, t}, \hat{\phi}_{c, t}, \hat{\phi}_{L, t}, \hat{\phi}_{R, 2008}\right\}$ to analyze impact of bank regulation on systemic risk after the global financial crisis.
} 


\section{Distribution}

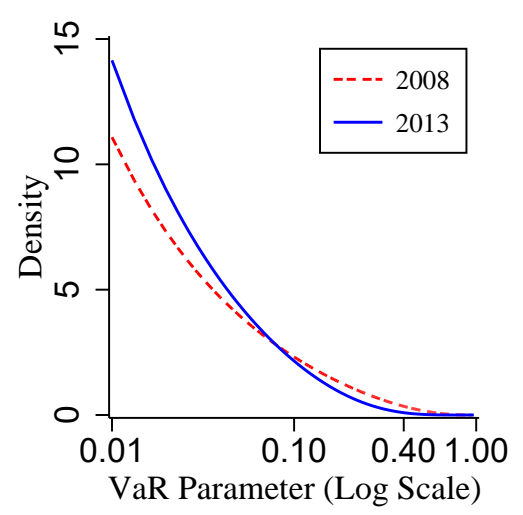

Distribution

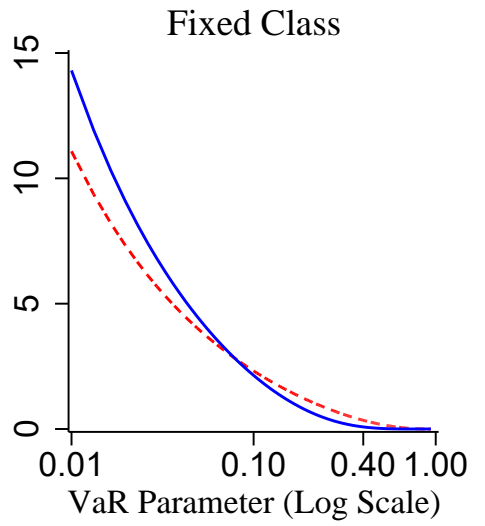

Distribution

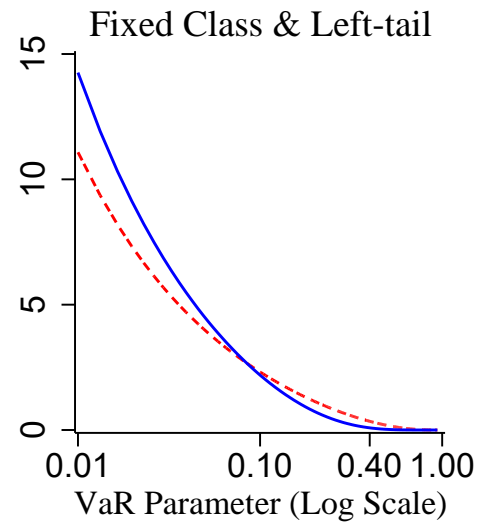

Figure 9: Distribution of Risk-Taking Behavior: The figure plots the estimated distribution of $\alpha_{i, t} \sim \phi_{c, t} \times \operatorname{Beta}\left(\phi_{L, t}, \phi_{R, t}\right)$ on $\left(0, \phi_{c, t}\right)$. We fix the class parameter as $\phi_{c, 2008}$ in the second figure. The third figure is done with the fixed class and left tail parameters as $\phi_{c, 2008}$ and $\phi_{L, 2008}$.

risk-taking behavior: $\tilde{\alpha}_{i, t}=\operatorname{ccdf}_{\alpha}^{-1}\left[\operatorname{ccdf}_{\alpha}\left(\hat{\alpha}_{i, t} \mid \hat{\Phi}_{t}\right) \mid \tilde{\Phi}_{t}\right]$.

- Step 3: Calculate the implied counterfactual leverage using $\tilde{\alpha}_{i, t}: \tilde{\lambda}_{i, t}=\lambda\left(\tilde{\alpha}_{i, t} \mid \tilde{\Phi}_{t}\right) .{ }^{33}$

- Step 4: Calculate the implied counterfactual assets using the observed equity and the implied leverage: $\tilde{a}_{i, t}=\omega_{i, t} \tilde{\lambda}_{i, t}$.

- Step 5: Calculate weighted and unweighted averages of $\tilde{\alpha}_{i, t}$. The weights are based on the counterfactual asset size $\tilde{a}_{i, t}$ and leverage $\tilde{\lambda}_{i, t}$, not the observed $a_{i, t}$ and $\lambda_{i, t}$ from the data. ${ }^{34}$

Figure 10 reports the benchmark systemic risk measures (solid black line with circles) and their counterfactual counterparts. As the solid black line with circles in the middle and right panels shows, financial instability measured by systemic risk decreased after the financial crisis. On the left pane of Figure 10, we also show the evolution of the estimated $\phi_{R, t}$ and

\footnotetext{
${ }^{33}$ The leverage for given risk behavior is: $\lambda\left(\tilde{\alpha} \mid \tilde{\Phi}_{t}\right)=\left\{1-\tilde{\phi}_{s, t}\left(\tilde{\phi}_{c, t}\right)^{-1 / \tilde{\phi}_{p, t}}[\tilde{\alpha} /(1-\tilde{\alpha})]^{1 / \tilde{\phi}_{p, t}}\right\}^{-1}$. That is independent of the left and right tail parameters: $\tilde{\phi}_{L, t}$ and $\tilde{\phi}_{R, t}$. We set the maximum value of leverage to be 1000 .

${ }^{34}$ In the case of $\tilde{\Phi}_{t}=\hat{\Phi}_{t}$, the procedure yields $\tilde{\alpha}_{i, t}=\hat{\alpha}_{i, t}, \tilde{a}_{i, t}=a_{i, t}$, and $\tilde{\lambda}_{i, t}=\lambda_{i, t}$ where assets $a_{i, t}$ and leverage $\lambda_{i, t}$ are observed from the data.
} 

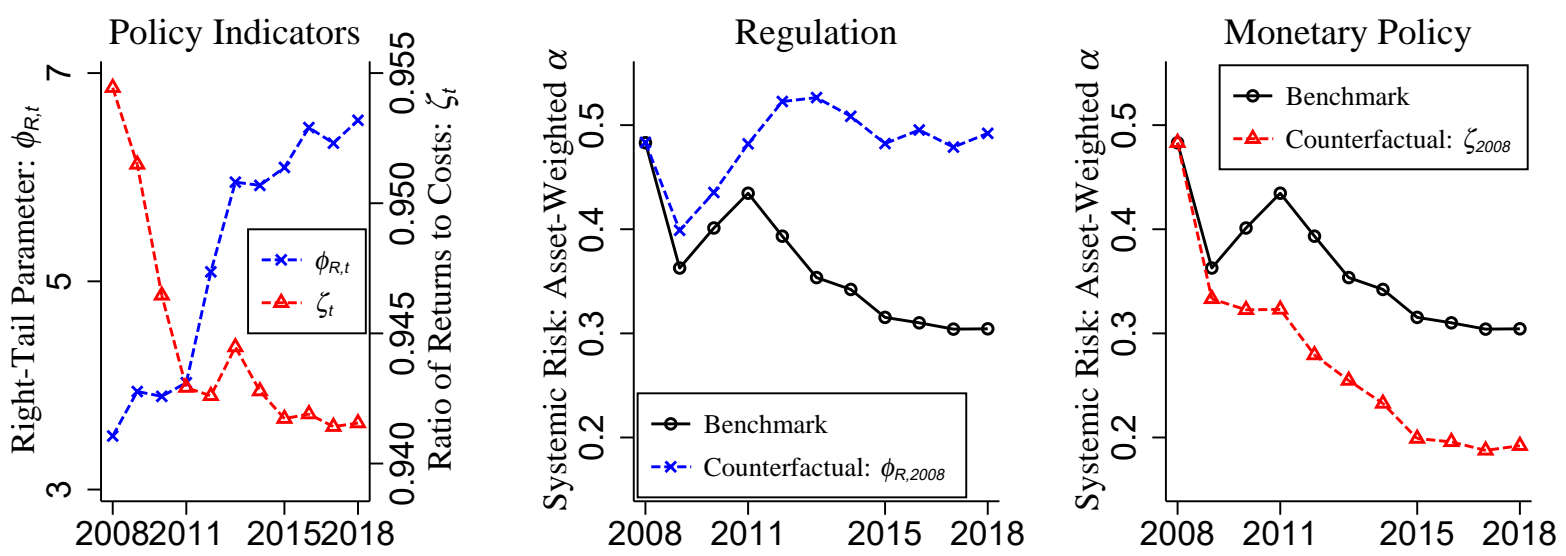

Figure 10: Counterfactual Analysis - Systemic Risk and Central Bank Policy: The first figure plots the estimated right tail parameter $\left(\hat{\phi}_{R, t}\right)$ and the ratio of expected returns to $\operatorname{costs}\left(\hat{\zeta}_{t}=\hat{\phi}_{s, t}\left(\hat{\phi}_{c, t}\right)^{-1 / \hat{\phi}_{p, t}}\right)$. The second and third figures plot the estimated systemic risk measure (asset-weighted mean of risk-taking) and its counterfactual values. The solid black lines are implied from the data and the estimates. The blue dash line with crosses is implied with the fixed value of the right tail index of risk-taking behavior $\left(\tilde{\phi}_{R, t}=\hat{\phi}_{R, 2008}\right)$. The red dash line with triangles is implied with the fixed value of the ratio of the expected returns of asset to the cost of funds $\left(\tilde{\phi}_{s, t}=\hat{\zeta}_{2008}\left(\hat{\phi}_{c, t}\right)^{1 / \hat{\phi}_{p, t}}\right)$.

$\zeta_{t}$ in this period. Since the financial crisis, the right tail parameter has trended upwards, indicating less concentration at the top of the risk-taking distribution. This could be due to the tightening of the post-crisis regulatory environment, including the implementation of Basel 3. The transition from 2008 to 2018 involves the right tail becoming steadily thinner. Figure 9 shows that the distributional changes are not due to changes in the class or left-tail parameter, as the middle and right panel distributions are extremely similar to the estimated ones in the left panel. Keeping the class or left tail parameters fixed at 2008 levels does not impact our systemic risk measure. Coming back to Figure 10, the spread $\zeta_{t}$ fell steadily in the years after the crisis and up to 2014. This indicates a loosening of funding conditions during this period, at which point it stabilized and even rose slightly but remained at much lower levels than in 2008.

In the first counterfactual, we set the right tail parameter that governs risk behavior to remain after the crisis at our 2008 estimates. The question we ask is therefore: "what would 
have happened ceteris paribus to systemic risk if the precrisis lax regulatory policies had stayed the same post-crisis?". The answer can readily be seen on the second panel of Figure 10 which reports the counterfactual systemic risk measure (in blue) next to the benchmark (in black). With a fixed right tail, systemic risk measures during 2011 and 2018 would be very similar to that of 2008 and, more generally, consistently above the benchmark. Without bank regulation, financial markets would struggle with instability which would remain near their 2008 peak. Financial stability improvements after the financial crisis were thus driven strongly by changes in the distribution tracked by the tail parameter and concerning high-risk intermediaries. Banking regulation constraining risk-taking in the right tail has been effective.

In the second counterfactual, we keep the spread, i.e., the ratio of expected returns on assets to costs of funds, equal to our 2008 estimates. The question we ask is therefore: "what would have happened ceteris paribus to systemic risk if the 2008 funding conditions had stayed the same instead of the very loose post-2009 monetary policy?". 35

The right panel of Figure 10 shows the benchmark measure of systemic risk (in black) with the counterfactual measure reflecting tighter funding conditions (in red). The 2018 benchmark systemic risk measure is considerably larger than that of the 2018 counterfactual. Without the expansionary monetary policy, financial markets would be more stable, as can be seen by the counterfactual systemic risk measure being consistently below the benchmark case. This illustrates monetary policy's trade-off between stimulating the economy (low interest rate) and financial stability. A fall in interest rates incentivizes intermediaries to take on more risk, which increases investment but also systemic risk. It is important to note that our counterfactual systemic risk measure drops below the sample minimum, which may not be desirable. Financial markets need a healthy degree of risk-taking to function normally. It is not only possible but likely that financial markets would have been too risk-averse with both tighter regulation and tighter funding conditions. It is important to note that we do not believe that the lower values of our measurements are always better; rather, values

\footnotetext{
${ }^{35}$ Table A7 report the counterfactual exercises with the highest and lowest level of the right tail parameter $\left(\phi_{R, t}\right) /$ the ratio of expected returns to costs $\left(\zeta_{t}\right)$ between 1993 and 2018.
} 
approaching the higher end of the sample indicate that financial stability concerns should be taken seriously. These results point to the importance of regulating and monitoring highrisk financial intermediaries. They also advocate for a degree of complementarity between monetary policy and macroprudential policies.

\section{Conclusion}

Financial stability and systemic risk have become essential concerns for monetary authorities worldwide. Measuring and tracking the financial system's stability requires indicators that reflect the degree of risk-taking among intermediaries. Although simple observable measures like leverage or credit growth can already provide meaningful information, they do not always track balance sheet risk. Credit growth can be driven by many different causes, such as, for example, more substantial investment opportunities or a fall in the cost of funds. Given observed aggregate credit and leverage growth, the implications for financial stability might be very different depending on the main driving cause.

In this paper, we make use of bank-level leverage data and a structural model to extract a distribution of intermediary risk-taking parameters. We use a simple Value-at-Risk (VaR) framework in which intermediaries endogenously choose leverage based on macroeconomic conditions (cost of funds, expected returns, and their volatility) and their characteristics. By exploiting the cross-sectional dynamics of leverage in the data, we are able to distinguish between different types of leverage booms and their implications for systemic risk. This way, we are able to infer macroeconomic and financial conditions without the need for additional variables. We show that our structural estimate of uncertainty is consistent with measures of long-run risk and that our risk-taking measures help predict the probability of intermediary distress/failure as well as its economic performance, including its cyclical and cross-sectional dynamics.

Using our estimates, we construct a simple measure of systemic risk by weighting banklevel risk-taking by its balance sheet size. This measure corresponds intuitively to the 
probability that a certain amount of assets are held by distressed investors. The measure rises significantly in the period before the financial crisis, peaks in 2008, and decreases going forward except before the euro area crisis. The weights serve an essential function because the measure reflects that growth in risk-taking among large intermediaries is more worrying than growth among smaller ones. They also allow us to highlight the importance of heterogeneity across financial intermediaries, as we can decompose the contribution to systemic risk of changes in average risk-taking and those arising from the heterogeneity around the mean. We show that heterogeneity within the financial sector plays a fundamental role in financial stability. The heterogeneous component drives most of the changes in our systemic risk measure. In contrast, the average component lags the crisis and is therefore not a good predictor by itself. Using a similar decomposition, we also show that changes in the systemic risk measure are driven mainly through banks in the top quantiles, particularly the top 5\% contributing up to $71 \%$ of the variance in the recent decades.

Finally, we explore different counterfactuals in order to highlight the important complementarity between monetary policy and financial regulation. Our first exercise shows that if regulation had not compressed the concentration of risk at the top of the distribution after the crisis, then systemic risk would have been post-crisis at much higher levels due to loose funding conditions. The counterfactual measure of systemic risk would have been closer to the 2008 crisis peak throughout the 2010s. In the second exercise, we show that loose monetary conditions tended to increase systemic risk after 2009; but they did not increase systemic risk significantly because of tighter macroprudential regulation.

To conclude, this paper provides empirical estimates of risk-taking at the financial intermediary level. It then constructs a measure of systemic risk that uses the heterogeneity in the cross-section of leverage to distinguish different types of leverage cycles. It can be used as an advance warning measure for macroprudential policies. Policy-makers can also use it to investigate the complementarity between monetary policy and macroprudential policies by constructing counterfactuals. First and foremost, it reveals the vital interplay between 
regulation and monetary policy, which determines financial stability. 


\section{References}

Adrian, Tobias, and Hyun Song Shin. 2010. "Chapter 12 - Financial Intermediaries and Monetary Economics." In . Vol. 3 of Handbook of Monetary Economics, , ed. Benjamin M. Friedman and Michael Woodford, 601-650. Elsevier.

Adrian, Tobias, and Markus K. Brunnermeier. 2016. "CoVaR." American Economic Review, 106(7): 1705-41.

Adrian, Tobias, and Nina Boyarchenko. 2012. "Intermediary Leverage Cycles and Financial Stability." FRB of New York Staff Report FRB of New York Staff Report 567.

Altavilla, Carlo, Miguel Boucinha, Jose-Luis Peydro, and Frank Smets. 2020. "Banking Supervision, Monetary Policy and Risk-Taking: Big Data Evidence from 15 Credit Registers." ECB Working Paper 2349.

Baron, Matthew, and Wei Xiong. 2017. "Credit Expansion and Neglected Crash Risk." The Quarterly Journal of Economics, 132(2): 713-764.

Barth, James R., and Stephen Matteo Miller. 2018. "Benefits and costs of a higher bank "leverage ratio"." Journal of Financial Stability, 38: 37-52.

Basel Committee on Banking Supervision. 2013. "Analysis of risk-weighted assets for market risk." Bank for International Settlements Regulatory Consistency Assessment Programmme Bank for International Settlements Regulatory Consistency Assessment Programmme.

Bloom, Nicholas, Max Floetotto, Nir Jaimovich, Itay Saporta-Eksten, and Stephen J. Terry. 2018. "Really Uncertain Business Cycles." Econometrica, 86(3): 10311065.

Borio, Claudio, and Philip William Lowe. 2002. "Asset Prices, Financial and Monetary Stability: Exploring the Nexus." BIS Working Paper BIS Working Paper 114.

Caballero, Ricardo J, and Alp Simsek. 2020. "A Risk-Centric Model of Demand Recessions and Speculation." The Quarterly Journal of Economics, 135(3): 1493-1566. 
Coimbra, Nuno, and Hélène Rey. 2020. "Financial Cycles with Heterogeneous Intermediaries." National Bureau of Economic Research Working Paper 23245.

Comin, Diego, and Thomas Philippon. 2005. "The Rise in Firm-Level Volatility: Causes and Consequences." NBER Macroeconomics Annual, 20: 167-201.

Cowell, Frank A., and Emmanuel Flachaire. 2015. "Chapter 6 - Statistical Methods for Distributional Analysis." In Handbook of Income Distribution. Vol. 2 of Handbook of Income Distribution, , ed. Anthony B. Atkinson and Francois Bourguignon, 359-465. Elsevier.

Cummins, J.David, Georges Dionne, James B. McDonald, and B.Michael Pritchett. 1990. "Applications of the GB2 family of distributions in modeling insurance loss processes." Insurance: Mathematics and Economics, 9(4): 257-272.

Dell'Ariccia, Giovanni, Luc Laeven, and Gustavo A. Suarez. 2017. "Bank Leverage and Monetary Policy's Risk-Taking Channel: Evidence from the United States." The Journal of Finance, 72(2): 613-654.

Dermine, Jean. 2006. "European Banking Integration: Don't Put the Cart before the Horse." Financial Markets, Institutions \&3 Instruments, 15(2): 57-106.

Drechsler, Itamar, Alexi Savov, and Philipp Schnabl. 2017. "The Deposits Channel of Monetary Policy." The Quarterly Journal of Economics, 132(4): 1819-1876.

Duarte, Fernando, and Thomas M. Eisenbach. 2021. "Fire-Sale Spillovers and Systemic Risk." The Journal of Finance, Forthcoming.

Eichengreen, Barry, and Richard Portes. 1987. "The anatomy of financial crises." In threats to international financial stability. , ed. Richard Portes and Alexander K. Swoboda, 10-58. Cambridge University Press.

Englund, Peter. 2016. "The Swedish 1990s Banking Crisis." Stockholm School of Economic Working Paper.

Farhi, Emmanuel, and Francois Gourio. 2018. "Accounting for Macro-Finance Trends: Market Power, Intangibles, and Risk Premia." 2 (Fall).

Forbes, Kristin J. 2021. "The International Aspects of Macroprudential Policy." Annual 
Review of Economics, 13.

Fouliard, Jeremy, Michael Howell, and Hélène Rey. 2020. "Answering the Queen: Machine Learning and Financial Crises." National Bureau of Economic Research Working Paper 28302.

Gerko, Elena, and Hélène Rey. 2017. "Monetary Policy in the Capitals of Capital." Journal of the European Economic Association, 15(4): 721-745.

Gertler, Mark, and Peter Karadi. 2015. "Monetary Policy Surprises, Credit Costs, and Economic Activity." American Economic Journal: Macroeconomics, 7(1): 44-76.

Gorton, Gary, and Guillermo Ordoñez. 2019. "Good Booms, Bad Booms." Journal of the European Economic Association, 18(2): 618-665.

Gourinchas, Pierre-Olivier, Hélène Rey, and Maxime Sauzet. 2019. "The International Monetary and Financial System." Annual Review of Economics, 11(1): 859-893.

Hellwig, Martin F. 2018. "Germany and the Financial Crises 2007 - 2017, Case Study on a Past Crisis: The Case of Germany." Swedish Riksbank Paper presented at the fourth Annual Macroprudential Conference.

Higbee, Joshua D., and James B. McDonald. 2021. "A comparison of the GB2 and skewed generalized log-t distributions with an application in finance." Journal of Econometrics.

Jimenez, Gabriel, Steven Ongena, Jose-Luis Peydro, and Jesus Saurina. 2014. "Hazardous Times for Monetary Policy: What Do Twenty-Three Million Bank Loans Say About the Effects of Monetary Policy on Credit Risk-Taking?" Econometrica, 82(2): 463505.

Kakamu, Kazuhiko, and Haruhisa Nishino. 2019. "Bayesian Estimation of Beta-type Distribution Parameters Based on Grouped Data." Computational Economics, 54(2): 625645 .

Kehrig, Matthias. 2015. "The Cyclical Nature of the Productivity Distribution." University of Texas at Austin Working Paper. 
McDonald, James B. 1984. "Some Generalized Functions for the Size Distribution of Income." Econometrica, 52(3): 647-663.

McDonald, James B., and Yexiao J. Xu. 1995. "A generalization of the beta distribution with applications." Journal of Econometrics, 66(1): 133-152.

Mian, Atif, and Amir Sufi. 2009. "The Consequences of Mortgage Credit Expansion: Evidence from the U.S. Mortgage Default Crisis." The Quarterly Journal of Economics, 124(4): 1449-1496.

Miranda-Agrippino, Silvia, and Hélène Rey. 2020. "U.S. Monetary Policy and the Global Financial Cycle." The Review of Economic Studies, 87(6): 2754-2776.

Parker, Simon C. 1999. "The generalised beta as a model for the distribution of earnings." Economics Letters, 62(2): 197-200.

Santos, Tano. 2017. "El Diluvio: The Spanish banking crisis, 2008-2012." Columbia University mimeo.

Schorfheide, Frank, Dongho Song, and Amir Yaron. 2018. "Identifying Long-Run Risks: A Bayesian Mixed-Frequency Approach." Econometrica, 86(2): 617-654.

Schularick, Moritz, and Alan M. Taylor. 2012. "Credit Booms Gone Bust: Monetary Policy, Leverage Cycles, and Financial Crises, 1870-2008." American Economic Review, 102(2): 1029-61.

Stulz, René M. 2016. "Risk management, governance, culture, and risk taking in banks." Economic Policy Review, Issue Aug: 43-60.

Vives, Xavier. 2000. "Chapter 8. Lessons from European Banking Liberalisation and Integration." In . The internationalization of financial services : issues and lessons for developing countries, ed. Stijn Claessens and Marion Jansen, 177-198. The Hague, Netherlands:Kluwer Law International.

Wilmarth, Arthur. 2014. "Citigroup: A case study in managerial and regulatory failures." Indiana Law Review, 47: 69-137. 


\section{Appendix}

\section{A. Data Construction}

We use annual bank (consolidated) balance sheet data from the Compustat Fundamentals Annual (North America, 1993 - 2018) databases via WRDS. Figures A2 - A4 in Appendix B present the number of observations and summary statistics of assets, equity, leverage, returns on assets and equity for the cleaned data by period.

We construct the database as follows. First, we keep the following observations.

- Consolidated: consol $=\mathrm{C}$.

- USD currency: $\operatorname{curcd}=\mathrm{USD}$.

- Not old entity: bank name (conm) is not tagged by OLD.

- No major mergers flag: Comparability status (compst) does not equal to $A B$.

Then, we we exclude financial intermediaries with the following criteria.

- Leverage is smaller than one: $\mathrm{at}_{i, t} /\left(\mathrm{at}_{i, t}-1 \mathrm{t}_{i, t}\right) \leq 1$.

- Extreme leverage (above 200): $a t_{i, t} /\left(a t_{i, t}-1 t_{i, t}\right) \geq 200$.

- Non-positive assets - total: at $t_{i, t} \leq 0$.

- Non-positive common/ordinary equity - total: ceql $_{i, t} \leq 0$.

- Non-positive common equity - tangible: ceqt $_{i, t} \leq 0$.

- Low assets (below 1 billion USD on average): $\left(1 / T_{i}\right) \sum_{t}$ at $_{i, t} \leq 1000$

- Low equity (below 1 million USD): at $\mathrm{t}_{i, t}-1 \mathrm{t}_{i, t} \leq 1$

- High repurchase agreements ratio to assets (above 0.9) $\left(\mathrm{ceqt}_{i, t} / \mathrm{at}_{i, t} \geq 0.9\right)$ 
Lastly, for ML estimation, we calculate the bottom ten (or five) percentile of leverage based on the whole sample of database from 1993 and to 2018 (not each year). Then, we drop all observations below the bottom ten percentile in our MLE procedure. In measuring systemic risk and doing counterfactual exercises, we do not exclude the bottom percentile.

Then, we calculate variables as follows.

- Assets: at

- Liability: $1 t$

- Equity: at - lt

- Leverage: at/(at - lt)

- RoA: ib/at

- RoE: ib/(at - lt)

To calculate annual stock returns, we collect monthly total returns (trt1m) from the Compustat Security Monthly (North America, 1992 - 2018). Then, we calculate stock returns in a fiscal year. We merge stock return data using cusip and datadate. 


\section{B. Additional Figures and Tables}

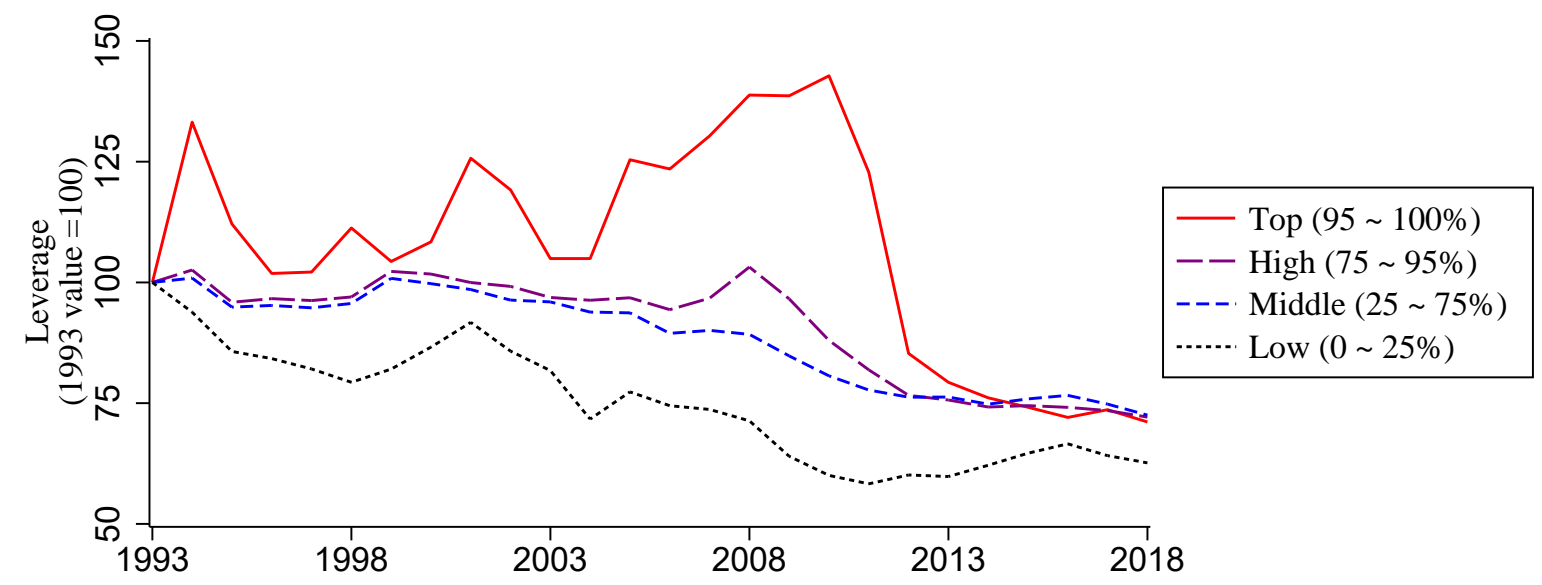

Figure A1: Evolution of unweighted leverage quantiles: The figure plots the average of the unweighted leverage's quantiles. Values were rebased to 100 for the starting year 1993, to highlight the stark difference in dynamics. 

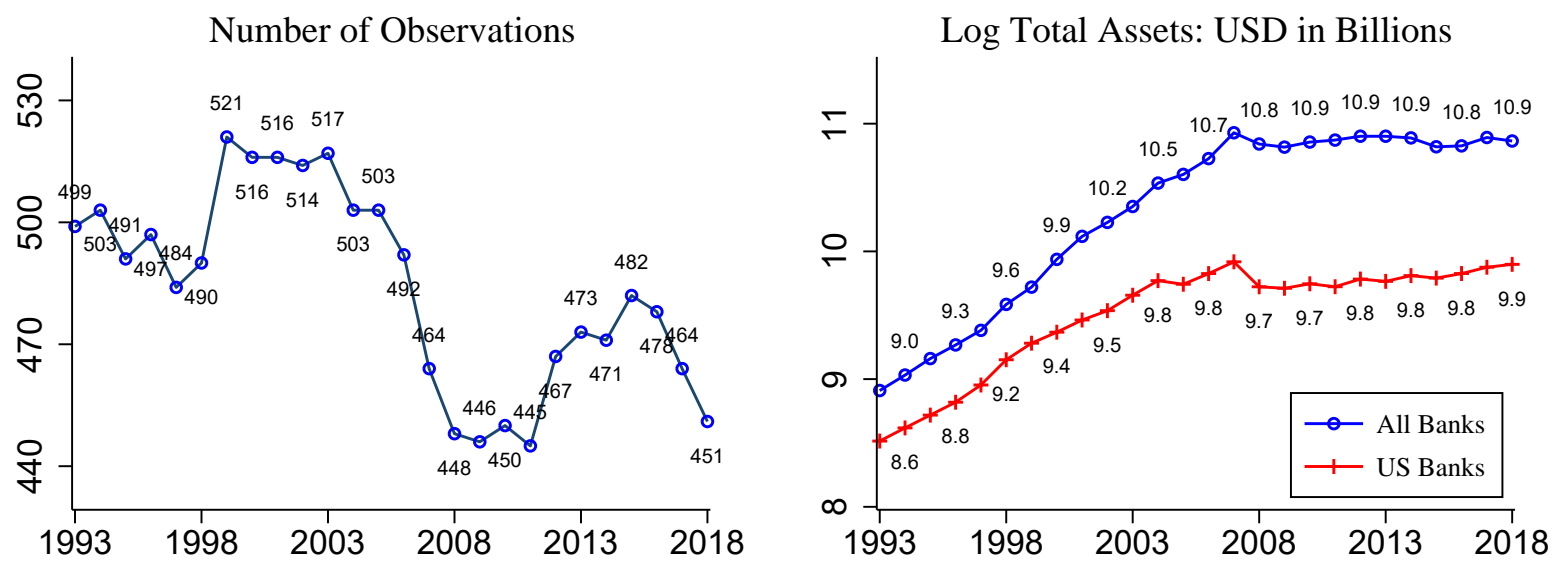

Mean and Median of Assets: USD in Billions
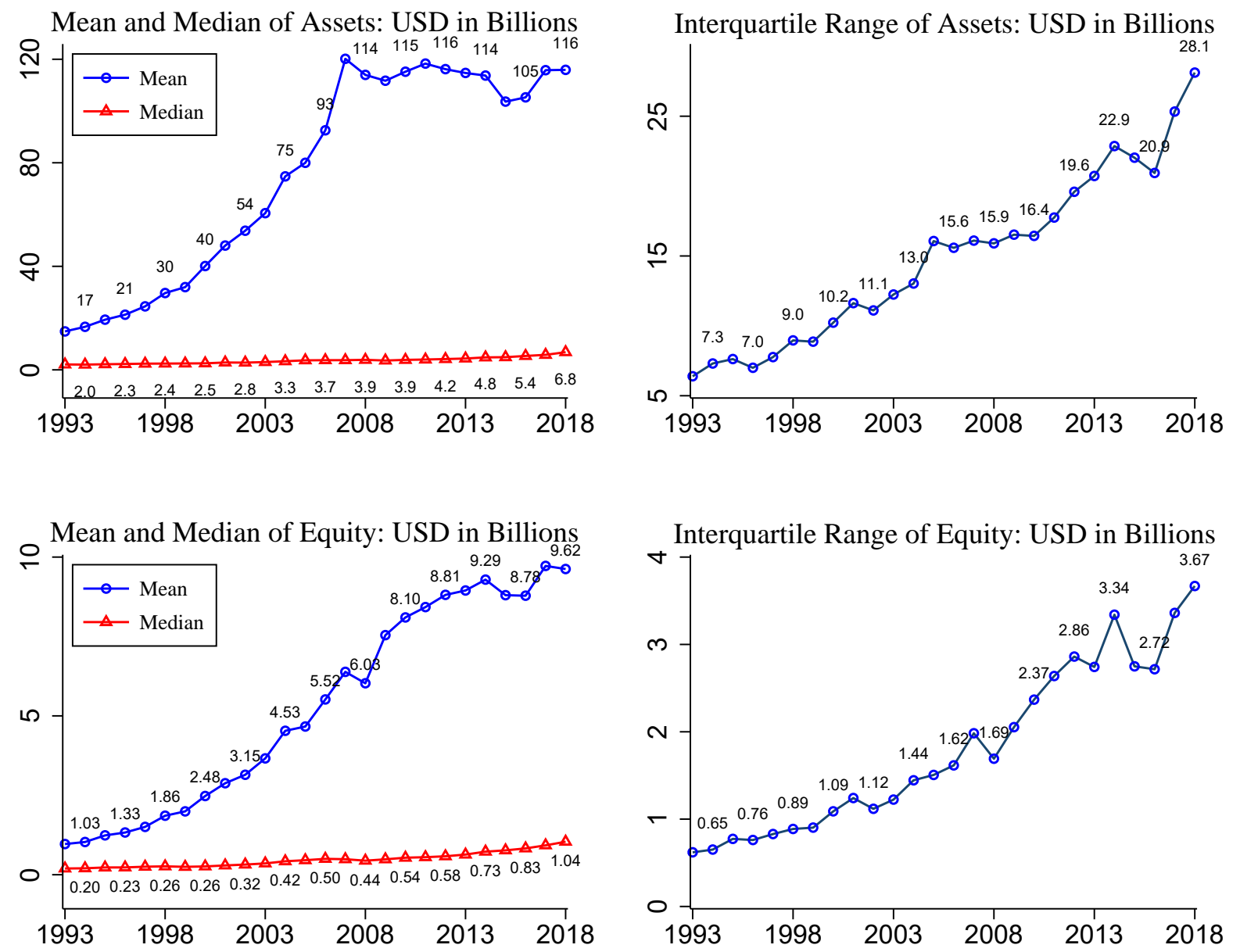

Figure A2: Summary Statistics I: Number of Observations, Assets, and Equity 

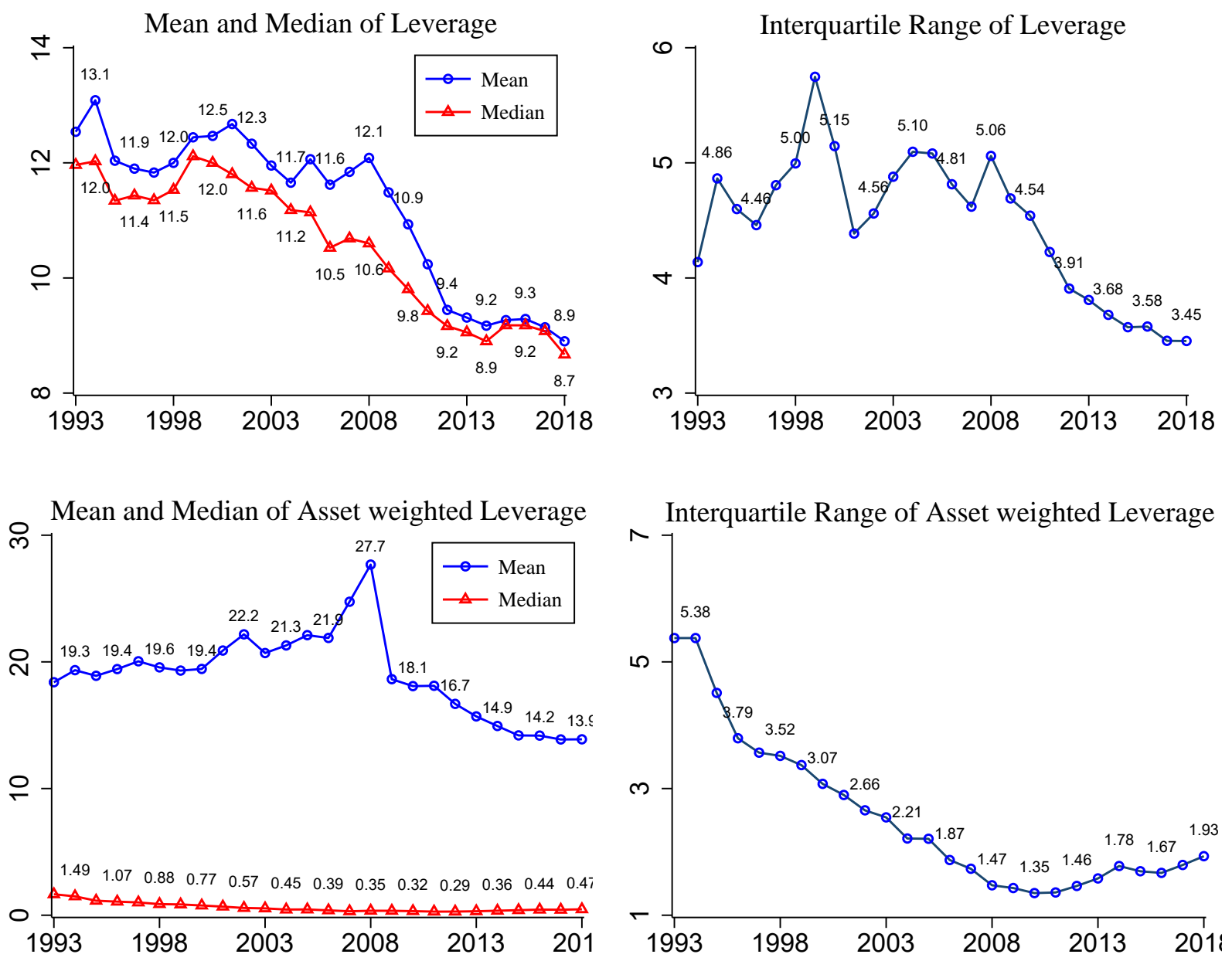

Figure A3: Summary Statistics II: Leverage and Asset-Weighted Leverage 

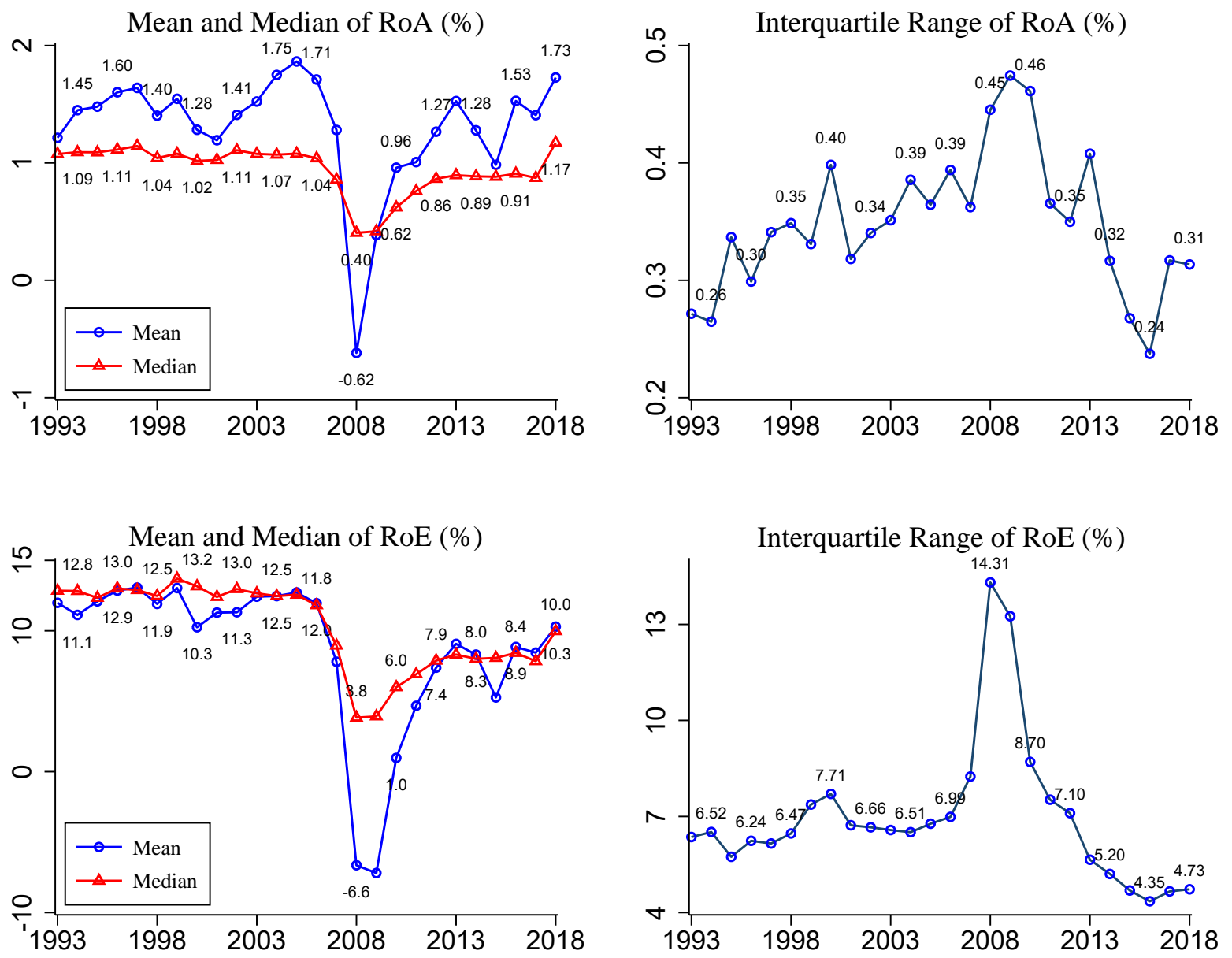

Figure A4: Summary Statistics III: Returns on Asset and Returns on Equity 

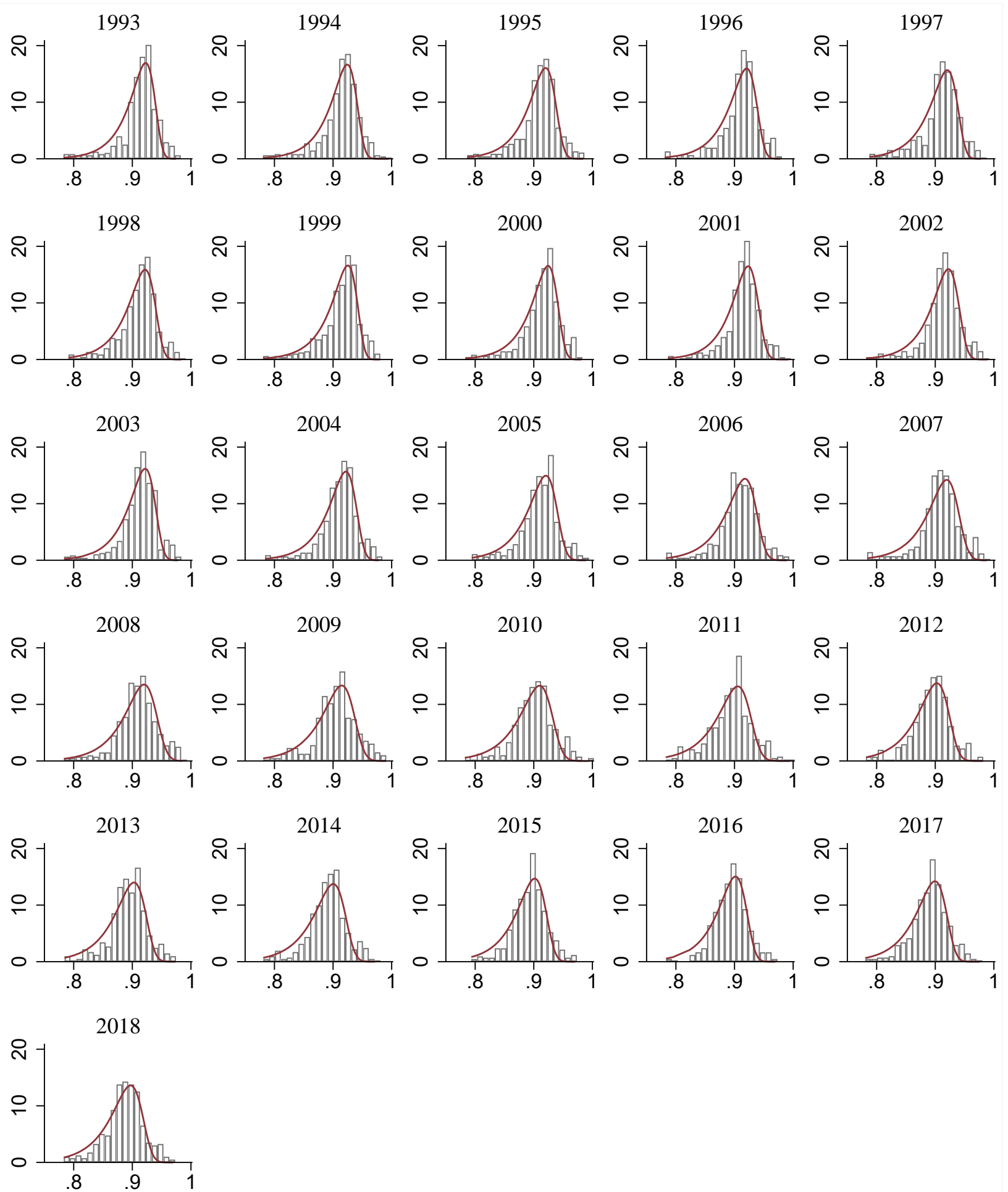

Figure A5: Estimated PDFs of Debt-to-Asset Ratio with Histograms: The red line plots the estimated probability density functions of debt-to-asset ratio with histograms (the width of bins to be 0.01 ). In this figure, we plot the debt-to-asset ratio by the bottom $10 \%$ (around 0.77 ). 


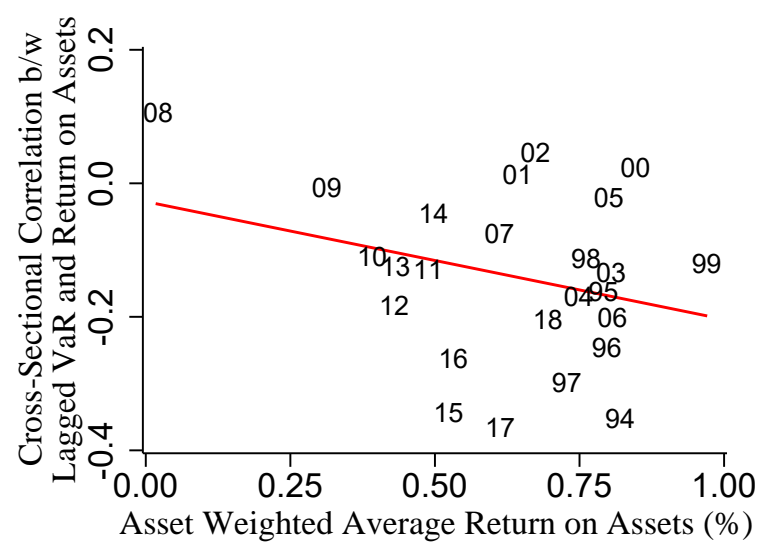

Figure A6: Risk-Taking Behavior and Return on Assets: The figures plot each year crosssectional correlation between a bank's lagged risk-taking measure $\left(\alpha_{i, t}\right)$ and its return on assets (the y-axis) and each period average return on assets of banks weighted by the assets (the x-axis).
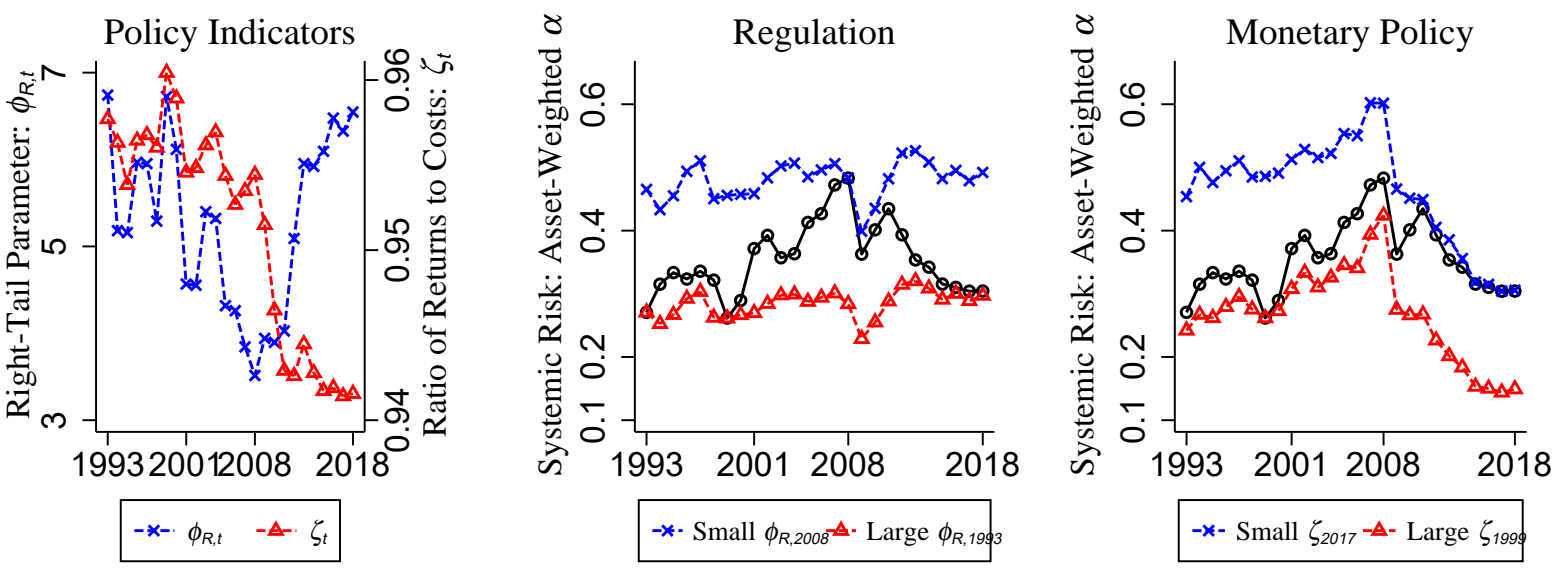

Figure A7: Systemic Risk and Counterfactuals: The figure plots estimated systemic risk measure (asset weighted mean of risk-taking) and its counterfactual values. The solid black lines with circles are implied from the data and the estimates. In the first figure, the blue dash lines with crosses and red dash lines with triangles are implied with the smallest (2008) and largest (1993) values of the estimated right tail index of risk-taking behavior $\left(\tilde{\phi}_{R, t}\right)$, respectively. In the second figure, the blue and red dash lines are implied with the smallest (2017) and largest (1999) values of the estimated the ratio of the expected returns of capital to the costs of funds $\left(\tilde{\zeta}_{t}\right)$, respectively. 


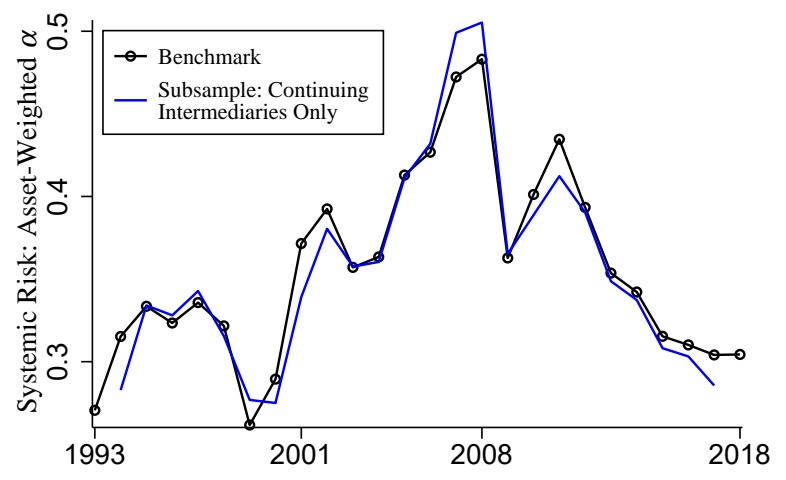

Figure A8: Systemic Risk with Continuing Financial Intermediaries: The figure plots estimated systemic risk measure (asset weighted mean of risk-taking) using data including and excluding exiting and entering financial intermediaries. The solid black line with circles is from the benchmark database including continuing, exiting, and entering intermediaries. The blue line is from the database including continuing intermediaries only but excluding exiting and entering intermediaries. At time $t$, the continuing intermediaries exist at $t-1, t$, and $t+1$. Exiting intermediaries exist at $t-1$ but not at $t$. Enterning intermediaries exist at $t$ but not at $t-1$. 
Table A1: Lists of the Top 20 Largest and Most Risk-Taking Banks

\begin{tabular}{|c|c|c|c|c|c|c|c|c|c|}
\hline \multirow[b]{2}{*}{ Bank Name } & \multicolumn{3}{|c|}{ Year: 2006} & \multicolumn{3}{|c|}{ Year: 2008} & \multicolumn{3}{|c|}{ Year: 2010} \\
\hline & $\overline{R a n k}$ & Size & Leverage & $\overline{\text { Rank }}$ & k Size & Leverage & $\overline{\text { Rank }}$ & Size & Leverage \\
\hline \multicolumn{10}{|l|}{ Panel A. Top 20 Largest Banks (Assets) } \\
\hline NATWEST GROUP PLC & 6 & 3.75 & 19.16 & 1 & 6.88 & 29.83 & 7 & 4.32 & 18.91 \\
\hline DEUTSCHE BANK AG & 9 & 3.26 & & 2 & 6.00 & & 2 & 4.88 & 37.82 \\
\hline BARCLAYS PLC & 2 & 4.29 & 36.39 & 3 & 5.88 & 43.30 & 5 & 4.42 & 23.93 \\
\hline BNP PARIBAS & 3 & 4.17 & 26.27 & 4 & 5.66 & 35.20 & 1 & 5.11 & 23.34 \\
\hline HSBC & 5 & 4.09 & 19 & 5 & 4.95 & 25.22 & 3 & 4.73 & 15.85 \\
\hline JPMC & 11 & 2.97 & & 6 & 4.26 & 3.03 & 8 & 4.08 & 12.02 \\
\hline MITSUBISHI & 8 & 3.48 & & 7 & 3.82 & 9.92 & 4 & 4.74 & 23.40 \\
\hline CITI & 4 & 4.14 & & 8 & 3.80 & & 10 & 3.69 & 11.54 \\
\hline UBS & 1 & 4.31 & & 9 & 3.70 & & 16 & 2.71 & 25.40 \\
\hline ING & 7 & 3.55 & & 10 & 3.63 & & 12 & 3.19 & 26.37 \\
\hline BAN & 10 & 3.20 & & 11 & 3.56 & & 6 & 4.37 & 9.92 \\
\hline SOCI & 14 & 2.77 & & 12 & 3.08 & & 15 & 2.90 & 22.21 \\
\hline MIZI & 13 & 2.80 & & 13 & 3.02 & & 9 & 3.75 & 24.28 \\
\hline $\mathrm{BAI}$ & 16 & 2.42 & & 14 & 2.86 & & 13 & 3.12 & 15.05 \\
\hline & 31 & 1.06 & & 15 & 2.57 & & 17 & 2.43 & 9.84 \\
\hline GR & 18 & 1.88 & & 16 & 2.36 & & 11 & 3.21 & 19.32 \\
\hline & 17 & 2.26 & & 17 & 2.15 & & 18 & 2.13 & 23.99 \\
\hline GO & 21 & 1.84 & & 18 & 1.73 & & 19 & 1.76 & 11.65 \\
\hline $\mathrm{BB}$ & 28 & 1.19 & & 19 & 1.48 & & 21 & 1.41 & \\
\hline $\mathrm{ME}$ & 20 & 1.85 & & 20 & 1.31 & & 23 & 1.20 & 12.40 \\
\hline Colur & 12.2 & 2.97 & & 10.5 & $5 \quad 3.63$ & & 11 & 3.41 & 19.10 \\
\hline \multicolumn{10}{|c|}{ Panel B. Top 20 Most Risk-Taking Banks (Asset-Weighted VaR Parameter) } \\
\hline DEUTSCHE BANK AG & 5 & 3.26 & & 1 & 6.00 & 1 & 1 & 4.88 & 37.82 \\
\hline & 2 & 4.29 & & 2 & 5.88 & & 4 & 4.42 & 23.93 \\
\hline $\mathrm{N}$ & 9 & 3.75 & & 3 & 6.88 & & 7 & 4.32 & 18.91 \\
\hline & 3 & 4.17 & & 4 & 5.66 & & 2 & 5.12 & 23.34 \\
\hline & 1 & 4.32 & & 5 & 3.70 & & 8 & 2.71 & 25.40 \\
\hline & 4 & 3.55 & & 6 & 3.63 & & 6 & 3.19 & 26.37 \\
\hline & 13 & 4.09 & & 7 & 4.95 & & 12 & 4.74 & 15.85 \\
\hline & 16 & 3.48 & & 8 & 3.82 & & 3 & 4.73 & 23.40 \\
\hline INC & 10 & 2.80 & & 9 & 3.02 & & 5 & 3.75 & 24.28 \\
\hline & 7 & 2.77 & & 10 & 3.08 & & 9 & 2.90 & 22.21 \\
\hline ANCIAL GR & 22 & 1.88 & & 11 & 2.36 & & 11 & 3.21 & 19.32 \\
\hline CREI & 12 & 2.26 & & 12 & 2.15 & & 13 & 2.13 & 23.99 \\
\hline & 14 & 1.48 & & 13 & 1.25 & & 10 & 2.94 & 21.14 \\
\hline & 23 & 1.07 & & 14 & 1.30 & & 15 & 1.10 & 30.68 \\
\hline & 17 & 1.85 & & 15 & 1.31 & 33.37 & 32 & 1.20 & 12.40 \\
\hline ANTANI & 21 & 2.42 & & 16 & 2.86 & & 14 & 3.12 & 15.05 \\
\hline BBVA & 27 & 1.19 & & 17 & 1.48 & 20.32 & 20 & 1.41 & 14.75 \\
\hline CITIGI & 15 & 4.14 & & 18 & 3.80 & 13.69 & 19 & 3.69 & 11.54 \\
\hline SAN $^{\prime}$ & 24 & 0.83 & & 19 & 0.66 & 48.17 & 16 & 0.90 & 24.67 \\
\hline JPM & 32 & 2.97 & & 20 & 4.26 & 13.03 & 18 & 4.09 & 12.02 \\
\hline Column Average & 13.85 & 2.83 & 25.90 & 10.5 & $5 \quad 3.40$ & 33.49 & 11.25 & 5.23 & 21.35 \\
\hline
\end{tabular}

Note: The size is defined by percentage share (\%) of a bank's assets in total assets of each year sample. In Panels A and B, the ranks are based on the size and asset-weighted VaR parameter, respectively, in each year. 
Table A2: Summary Estimates of Distribution

\begin{tabular}{lrrrrrrr}
\hline & & & & & \multicolumn{3}{c}{ Quartiles } \\
\cline { 6 - 8 } & Mean & S.D. & Min & Max & $25 \%$ & $50 \%$ & $75 \%$ \\
\hline Full Period: $1993-2018$ & & & & & & & \\
$\phi_{p t}:$ power & 67.231 & 7.556 & 57.168 & 80.062 & 59.624 & 66.322 & 73.057 \\
$\phi_{s t}:$ scale & 0.951 & 0.006 & 0.941 & 0.960 & 0.942 & 0.953 & 0.956 \\
$\phi_{c t}:$ class & 0.964 & 0.008 & 0.942 & 0.978 & 0.960 & 0.964 & 0.970 \\
$\phi_{L t}:$ left-tail shape & 0.410 & 0.019 & 0.364 & 0.434 & 0.395 & 0.417 & 0.424 \\
$\phi_{R t}:$ right-tail shape & 5.276 & 1.001 & 3.515 & 6.742 & 4.318 & 5.307 & 6.094 \\
\hline Period I: 1993-2000 & & & & & & & \\
$\phi_{p t}:$ power & 75.786 & 3.103 & 72.499 & 80.062 & 72.969 & 75.428 & 78.466 \\
$\phi_{s t}:$ scale & 0.957 & 0.002 & 0.953 & 0.960 & 0.956 & 0.956 & 0.958 \\
$\phi_{c t}:$ class & 0.965 & 0.003 & 0.962 & 0.970 & 0.962 & 0.964 & 0.968 \\
$\phi_{L t}:$ left-tail shape & 0.386 & 0.012 & 0.364 & 0.406 & 0.383 & 0.384 & 0.392 \\
$\phi_{R t}:$ right-tail shape & 5.892 & 0.641 & 5.159 & 6.742 & 5.236 & 5.960 & 6.421 \\
\hline Period II: 2001-2008 & & & & & & & \\
$\phi_{p t}:$ power & 68.007 & 5.047 & 59.603 & 73.363 & 64.039 & 69.386 & 72.120 \\
$\phi_{s t}:$ scale & 0.954 & 0.001 & 0.952 & 0.956 & 0.953 & 0.954 & 0.955 \\
$\phi_{c t}:$ class & 0.958 & 0.008 & 0.942 & 0.968 & 0.955 & 0.959 & 0.964 \\
$\phi_{L t}:$ left-tail shape & 0.415 & 0.010 & 0.402 & 0.431 & 0.407 & 0.414 & 0.422 \\
$\phi_{R t}:$ right-tail shape & 4.472 & 0.653 & 3.515 & 5.400 & 4.052 & 4.435 & 4.945 \\
\hline Period III: $2009-2018$ & & & & & & & \\
$\phi_{p t}:$ power & 59.765 & 1.938 & 57.168 & 63.380 & 58.160 & 59.393 & 60.621 \\
$\phi_{s t}:$ scale & 0.943 & 0.003 & 0.941 & 0.951 & 0.941 & 0.942 & 0.944 \\
$\phi_{c t}:$ class & 0.969 & 0.008 & 0.951 & 0.978 & 0.966 & 0.970 & 0.975 \\
$\phi_{L t}:$ left-tail shape & 0.425 & 0.006 & 0.415 & 0.434 & 0.420 & 0.425 & 0.430 \\
$\phi_{R t}:$ right-tail shape & 5.427 & 1.093 & 3.895 & 6.546 & 4.027 & 5.937 & 6.327 \\
\hline
\end{tabular}

Table A3: Risk-Taking Behavior and Stock Returns: Bull vs Bear Markets

\begin{tabular}{lcccccc}
\hline & \multicolumn{5}{c}{ One Year Ahead Excess Stock Returns: $r_{i, t+1}^{\text {stock }}=r_{i, t+1}^{\text {stock }}-\bar{r}_{t+1}^{\text {stock }}$} \\
\cline { 2 - 7 } Sample & $(1)$ & $(2)$ & $(3)$ & $(4)$ & $(5)$ & $(6)$ \\
\hline VaR parameter $(\log )$ & $\bar{r}_{t+1}^{\text {stock }}>0$ & $\bar{r}_{t+1}^{\text {stock }} \leq 0$ & $\bar{r}_{t+1}^{\text {stock }}>0$ & $\bar{r}_{t+1}^{\text {stock }} \leq 0$ & $\bar{r}_{t+1}^{\text {stock }}>0$ & $\bar{r}_{t+1}^{\text {stock }} \leq 0$ \\
& $1.00^{* * *}$ & 0.00 & $1.97^{* * *}$ & $0.36^{*}$ & $1.69^{* * *}$ & $0.25^{* * *}$ \\
& $(0.30)$ & $(0.10)$ & $(0.32)$ & $(0.20)$ & $(0.03)$ & $(0.02)$ \\
\hline Other Controls & No & No & Yes & Yes & Yes & Yes \\
Bank FE & Yes & Yes & Yes & Yes & Yes & Yes \\
Year FE & Yes & Yes & Yes & Yes & No & No \\
Year-Bank Type FE & No & No & No & No & Yes & Yes \\
Year-Country FE & No & No & No & No & Yes & Yes \\
Observations & 5616 & 2461 & 4755 & 2074 & 4583 & 1998 \\
R-squared & 0.28 & 0.36 & 0.39 & 0.44 & 0.49 & 0.52 \\
\hline
\end{tabular}

Note: ${ }^{*} p<0.1,{ }^{* *} p<0.05,{ }^{* * *} p<0.01$. Standard errors (in parentheses) are clustered at the country-bank type level. Singleton observations are dropped in all regressions. The estimation is based on equation (7). The dependent variable is the excess stock return. Other controls are dividend yield, a book to market ratio, and asset size in logs. 